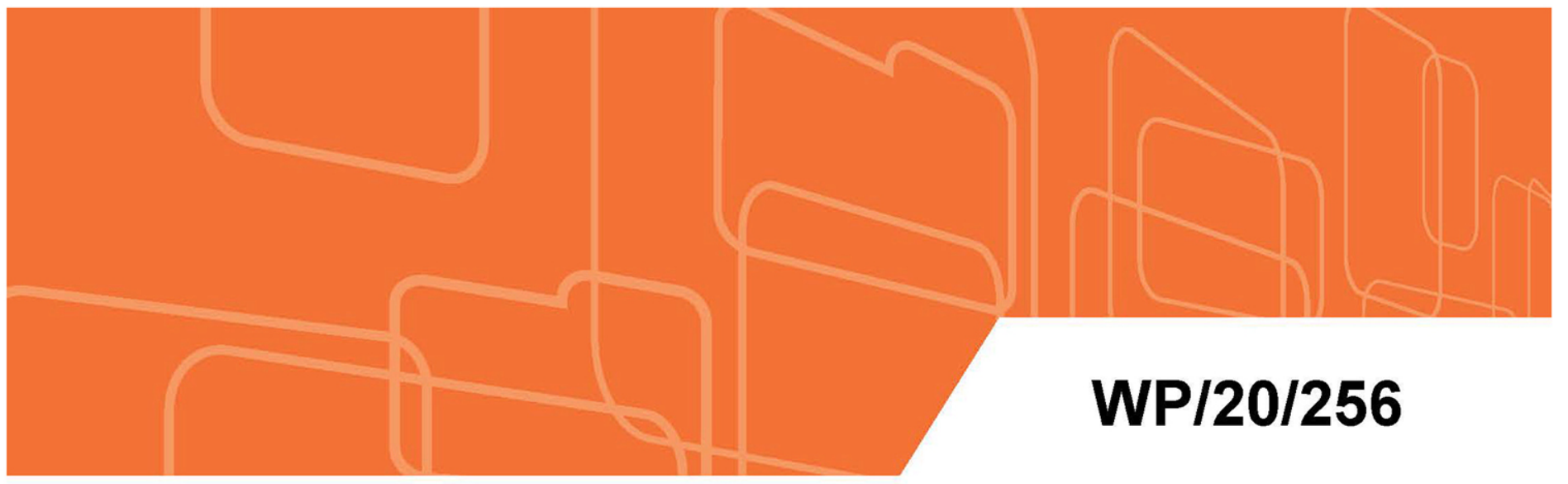

IMF Working Paper

\title{
Labor Market Informality and the Business Cycle
}

by Frederic Lambert, Andrea Pescatori, and Frederik Toscani

IMF Working Papers describe research in progress by the author(s) and are published to elicit comments and to encourage debate. The views expressed in IMF Working Papers are those of the author(s) and do not necessarily represent the views of the IMF, its Executive Board, or IMF management. 


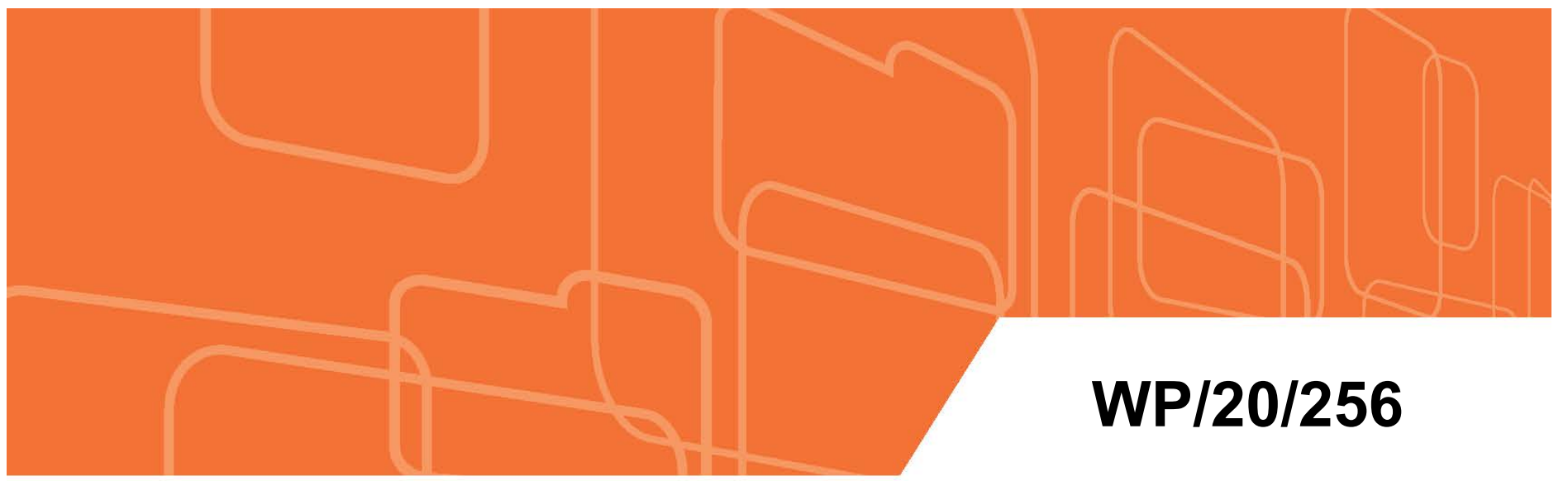

\section{IMF Working Paper}

\section{Labor Market Informality and the Business Cycle}

by Frederic Lambert, Andrea Pescatori, and Frederik Toscani

IMF Working Papers describe research in progress by the author(s) and are published to elicit comments and to encourage debate. The views expressed in IMF Working Papers are those of the author(s) and do not necessarily represent the views of the IMF, its Executive Board, or IMF management. 


\title{
IMF Working Paper
}

Western Hemisphere Department

\section{Labor Market Informality and the Business Cycle}

\section{Prepared by Frederic Lambert, Andrea Pescatori, and Frederik Toscani ${ }^{1}$}

Authorized for distribution by Jorge Roldos

November 2020

\begin{abstract}
IMF Working Papers describe research in progress by the author(s) and are published to elicit comments and to encourage debate. The views expressed in IMF Working Papers are those of the author(s) and do not necessarily represent the views of the IMF, its Executive Board, or IMF management.
\end{abstract}

\begin{abstract}
Labor market informality is a pervasive feature of most developing economies. Motivated by the empirical regularity that the labor informality rate falls with GDP per capita, both at business cycle frequency and in a cross-section of countries, and that the Okun's coefficient falls with the level of labor informality, we build a small open-economy dynamic stochastic general equilibrium model with two sectors, formal and informal, which can replicate these key stylized facts. The model is calibrated to Colombia. The results show that labor market and tax reforms play an important role in changing the informality rate but also caution against over-optimism - with low GDP per capita, informality will always be relatively high as there is insufficient demand for formal goods. Quantitatively we find that higher productivity in the formal sector is key in explaining the difference between Colombia and countries with significantly lower informality. We use the model to study how labor informality and labor market frictions mediate the cyclical response of the economy to shocks, including commodity price shocks which are particularly relevant in Latin America. Informality is shown to play an important role as a shock absorber with the informal-formal margin limiting movements in the employed-unemployed margin.
\end{abstract}

JEL Classification Numbers: E26, E32, J20, J46

Keywords: labor market; informality; business cycle

Author’s E-Mail Address: flambert@imf.org; apescatori@imf.org; ftoscani@imf.org

\footnotetext{
${ }^{1}$ We thank Emilio Fernandez Corugedo, Jorge Roldos, and Kevin Wiseman for helpful comments.
} 


\section{Introduction}

Informality is a reality across the World's economies. According to the International Labor Organization, more than 60 percent of the World's workers are employed in the informal economy ranging from around 90 percent in Benin to 5 percent in Iceland and Finland (ILO, 2018). In a typical developing country, 35 percent of GDP is produced in the informal sector and the sector employes 70 percent of the labor force (Loayza, 2016).

Broadly, we can think of informality as economic agents operating outside the framework of norms and regulations defined by the state. This is a problem in and of itself as long as the set of norms and regulations serves a desirable purpose. For example, workers in the informal sector might not benefit from the protections and conditions intended to guarantee acceptable working conditions. Similarly, the lack of tax collection from the informal sector can hamper the state's ability to provide public goods. ${ }^{1}$

The macroeconomic impact of informality is less clear ex ante but is likely to be important. Informality provides de facto flexibility which might be beneficial for growth if regulations are burdensome. But it can also hinder growth through various channels, including the lack of public goods as mentioned above, distorted firm decisions (e.g., staying small to stay hidden) and allowing unproductive firms to survive, thus distorting the allocation of resources further (Ulyssea, 2018).

In this paper we build a dynamic stochastic general equilibrium model that is consistent with the empirical patterns of informality at both the business cycle and long run frequencies. In particular, the model is able to replicate three key stylized facts: (i) Labor market informality is lower in richer countries and declines as a country gets richer, (ii) labor market informality is countercyclical, (iii) unemployment reacts more to the business cycle when informality is lower (larger Okun's coefficient).

We combine elements of the existing literature focused on steady state comparisons and business cycle dynamics. Influential recent papers such as Meghir, Narita, and Robin (2015), Ulyssea (2010) and Ulyssea (2018) investigate the interactions between economic policy, informality, output and TFP in steady state by introducing heterogeneous firms that can choose whether to comply with the relevant laws and regulations. ${ }^{2}$ To combine business cycle dynamics with steady state comparative analysis, we simplify some elements in the above papers. In our framework, heterogeneity is confined to introducing a formal and informal sector that produce different goods taking TFP as an exogenous process. ${ }^{3}$ Another strand of the literature focuses more narrowly on studying the role of informality

\footnotetext{
${ }^{1}$ Perry, Maloney, Arias, Fajnzylber, Mason, and Saavedra-Chanduvi (2007) provides an extensive discussion of the causes of informality and its implications for growth in Latin America.

${ }^{2}$ See Rauch (1991) for an important early contribution.

${ }^{3}$ Some mapping between heterogeneous firm models and our approach is nevertheless possible. Varying the exogenous TFP parameter in our model is akin to varying the exogenous mean of the firm TFP distribution in a heterogeneous firm world. The endogeneity of TFP in heterogeneous firm models stems from the TFP cutoff for firms which choose to enter the market and the formal sector while the mean of ex ante firm distribution is given.
} 
over the business cycle and includes Leyva and Urrutia (2020), Bosch and Esteban-Pretel (2012) and Restrepo-Echavarria (2014). ${ }^{4}$ These papers typically analyze a particular country and do not aim to explain cross-country variation. For example, in a recent model of the Mexican economy, Leyva and Urrutia (2020) show that informality adds flexibility to the economy in adjusting to domestic and international shocks, but at the cost of an excess output volatility - results mirrored in our own analysis.

Our modeling framework builds most directly on Anand and Khera (2016) and Munkacsi and Saxegaard (2017). The model includes a representative household that consumes formal and informal goods and supplies labor, perfectly competitive intermediate good producers, monopolistic competitive wholesale final good producers, retailers, capital producers, and a public sector (government and a monetary authority). Formal and informal firms (which produce formal and informal goods, respectively) face different frictions in terms of entry costs, hiring costs and payroll taxes and while informal goods can only be consumed by domestic households, formal goods can also be exported and consumed by the government.

We specify the utility function such that there is a zero-income effect on the consumption of the informal good. This captures the so-called demand-channel of informality as laid out by La Porta and Shleifer (2014) among others.The idea of the demand channel is simple. Entrepreneurs who want to modernize their business need to generate sufficient sales to cover the fixed costs of investment. When income is low, demand for formal goods may be too low to cover fixed costs. Demand for low-quality, cheap informal goods expands the informal sector at the cost of the formal sector. As we will show, this mechanism is important to allow the model to generate a decreasing, concave empirical relationship between informality and GDP per capita (stylized fact (i)). Formal sector TFP is the key model parameter which allows us to match the shape of the curve as it is in the data. However, changes in aggregate TFP create a slope that is too 'flat' - informality does not fall sufficiently fast as GDP per capita increases. Taken at face value this provides information on the role of TFP in development. Rather than both formal and informal sector TFP increasing handin-hand, the model suggests that development is associated with a larger and larger gap between formal and informal sector TFP as the former grows and the latter stagnates.

The model is also able to replicate the additional two stylized facts - labor informality is countercyclical and the Okun's coefficient decreases with the level of labor informality. The intuition for the fall in the Okun's coefficient comes from the role informality can play as a shock absorber. Rather than having only one margin of adjustment (employed-unemployed), informality allows for a second margin (formal employment - informal employment). The larger the informal sector, the more important that second margin. ${ }^{5}$ To the best of our knowledge the three stylized facts could

\footnotetext{
${ }^{4}$ Also see Castillo and Montoro (2012). Bosch and Maloney (2008) presents an influential description of informality over the business cycle.

${ }^{5}$ Labor force participation offers an additional margin that is not captured in the model. For an empirical discussion of the importance of the three margins of labor market adjustment in Latin America, see David, Lambert, and Toscani (2019).
} 
not be jointly captured in most existing models.

We use our modeling framework to study both the impact of structural reforms on steady state outcomes and the role of informality and labor market frictions for business cycle dynamics. In particular, we calibrate the model to replicate the Colombian economy (with parameters which determine business cycle moments estimated using a simulated method of moments) and then focus on how informality reacts to and mediates shocks over the business cycle. ${ }^{6}$ We find that higher formal sector productivity is necessary to substantially reduce labor informality, but labor market reform is key to reduce the steady state unemployment rate.

TFP and commodity price shocks prove to be the most important shocks to match business cycle moments for Colombia. Impulse response functions for both shocks display the expected reaction of macroeconomic variables. Unemployment, labor informality, and output informality are shown to be counter-cyclical. To better understand how the level of informality and labor market frictions affect labor market dynamics, we compare the reaction of three economies to the shocks (i) our baseline economy, representing Colombia, (ii) Colombia with lower labor market frictions, and (iii) Colombia with higher formal sector TFP (the "rich" economy). Steady state informality is set equal in (ii) and (iii) for a cleaner comparison. A higher level of informality, ceteris paribus and conditional on TFP or commodity price shocks, mitigates business cycle fluctuations in GDP and, especially, in consumption and unemployment. This is an important consideration given that higher levels of informality are also associated with a less sizable welfare state.

The remainder of this paper is organized as follows. Section 2 briefly reviews three stylized facts which our model aims to replicate. Section 3 provides an overview of the model while section 4 describes the baseline model estimation. Section 5 presents the results. Section 6 concludes. A full description of the model can be found in Appendix A while additional tables on model calibration and estimation are presented in Appendix B.

\section{Stylized facts}

There are three well-established stylized facts which we will want the model to replicate: (i) Labor market informality is lower in richer countries and labor market informality declines as a country gets richer, (ii) labor market informality is counter-cyclical at business cycle frequency, (iii) unemployment reacts more to the business cycle when informality is lower. La Porta and Shleifer (2014) and Bosch and Maloney (2008), respectively, discuss these in some detail.

To briefly illustrate the three points consider Figure 1 and 2 as well as Table 1. Some of the exercises underlying the figures and tables draw on our work in David et al. (2019). ${ }^{7}$

\footnotetext{
${ }^{6}$ Important references for our calibration of the model to Colombia are Daza and Gamboa (2013), Fernandez, Gonzalez, and Rodriguez (2018) and Gonzales, Lopez, Rodriguez, and Tellez (2013).

${ }^{7}$ Time-series labor informality data for Latin American countries come from the Inter-American Development
} 
Figure 1 visualizes stylized fact (i). In the top graph, the level of labor informality as defined by the ILO (2018) is plotted against GDP per capita in USD from the World Bank (all data are for 2016). The strong, convex, negative relationship between the two is immediately obvious. But this pure cross-sectional graph does not tell us anything about how informality changes as a country becomes richer. The bottom graph completes the picture by showing labor informality and GDP per capita over time for several Latin American countries. ${ }^{8}$ All of them (with the notable exception of Mexico) show a clear negative relationship between informality and GDP. But of course Figure 1 also makes it clear that GDP per capita is not the whole story - countries with the same level of GDP per capita can have substantially differing levels of informality, especially for intermediate levels of development.

To illustrate stylized fact (ii), Table 1 shows the negative correlation between informality and GDP over the business cycle at annual frequency - informality is shown to be strongly counter-cyclical. ${ }^{9}$

Finally, Figure 2 documents stylized fact (iii) - unemployment reacts less to the business cycle (a smaller Okun's coefficient in absolute value) when informality is higher. To construct the figure, we regress the change in the unemployment rate on GDP growth and one lag of GDP growth. We then sum the two coefficients and plot them against the level of informality in $2016 .{ }^{10}$ As the graph shows, the importance of the employment-unemployment margin declines as the informalformal margin becomes more important. In countries with the highest level of informality, the formal-informal margin nearly fully replaces the employed-unemployed margin leading to very low estimated Okun's coefficients. ${ }^{11}$

Banks (IDB) SIMS database (Labor Market and Social Security Information System). Data are harmonized across countries; the working age population is defined as the population between ages 15 and 64 . Cross-sectional labor informality data come from the International Labor Organization (we focus on the share of informal employment in total non-agricultural employment). Labor informality rates can differ by several percentage points depending on the definition used, as illustrated by the differences in informality rates in large Latin-American countries between Figure 1a and 1b. Moreover, the data shown in this paper can differ from those published by the statistical agencies of individual countries.

${ }^{8}$ Historical informality data are not available in a consolidated dataset. We thus focus exclusively on Latin America, using harmonized household survey data compiled by the Inter-American Development Bank. As shown by the dots highlighted with a red cross in Figure 1a, large Latin American countries tend to have higher informality rates than implied by their level of GDP per capita.

${ }^{9}$ Unfortunately, data constraints do not allow us to show correlations at quarterly frequency using harmonized data. We thus use annual data from the Inter-American Development Bank. Data for Chile and Mexico are only available for every second year and those countries are thus excluded from the table.

${ }^{10}$ While we just showed that informality moves with the cycle and thus picking data for 2016 - the cross-section with the best data availability - might appear problematic, the correlation would look very similar at different points in time given informality is a slow-moving variable in absolute terms.

${ }^{11}$ David et al. (2019) and IMF (2019) have a more detailed discussion. 
Figure 1: Stylized Fact (i) - Informality falls with Development (GDP per capita)

(a) Cross-country relationship between Labor Informality and GDP per capita

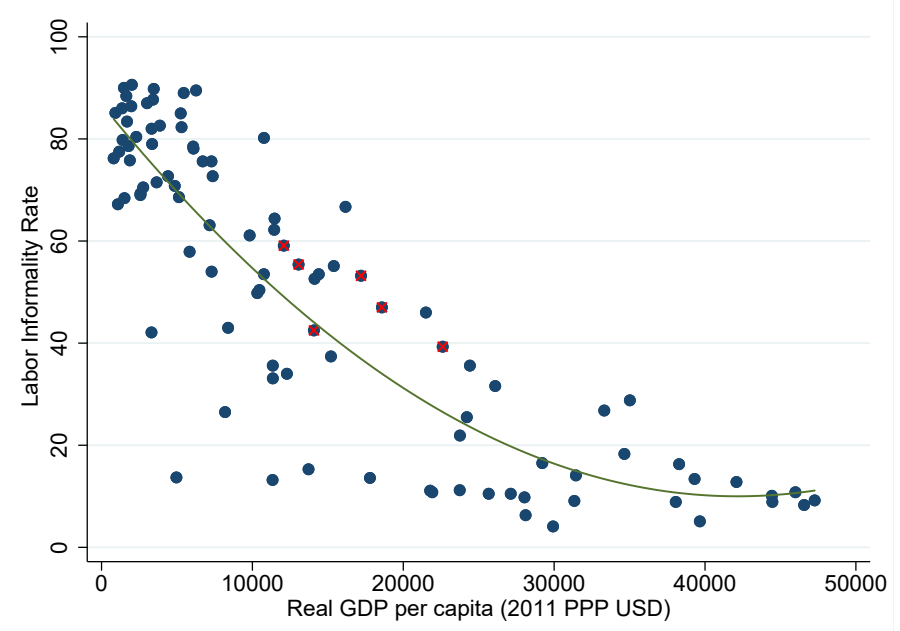

(b) Informality and GDP per capita across countries and over time in Latin America

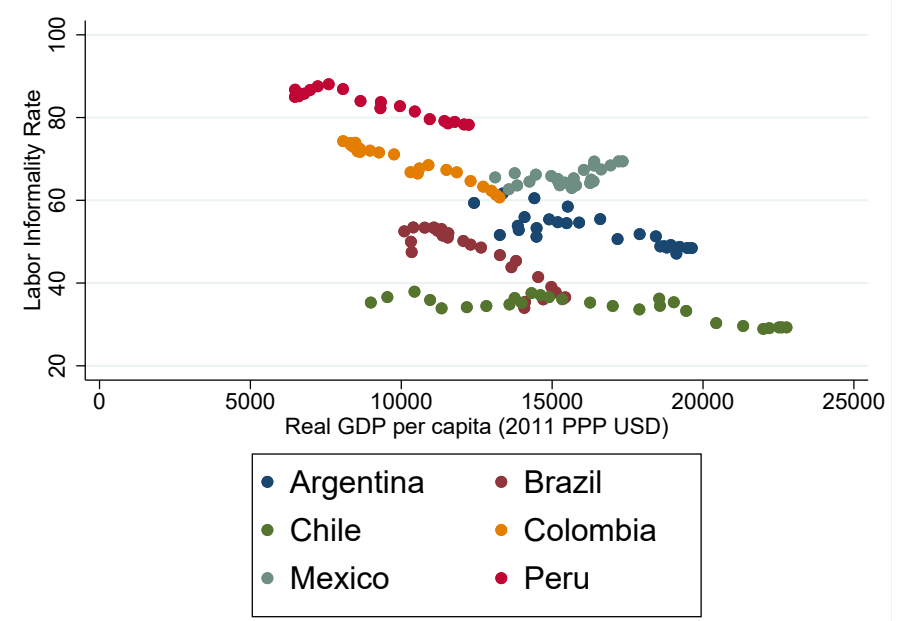

Note: Informality data in panel (a) are from the International Labor Organization. The red crosses highlight Argentina, Brazil, Chile, Colombia, Peru and Mexico. The same set of countries is shown over time in panel (b), using data from the Inter-American Development Bank. 
Table 1: Stylized Fact (ii) - Informality is counter-cyclical

\begin{tabular}{lcc}
\hline \hline & Correlation $\left(\ln \Delta G D P \Delta L_{I} / L\right)$ & Correlation $\left(\ln G D P L_{I} / L\right)$ \\
\hline & & \\
Brazil & -0.12 & -0.96 \\
Colombia & -0.75 & -0.95 \\
Peru & -0.34 & -0.92 \\
\hline \hline Average & -0.4 & -0.94 \\
\hline \hline
\end{tabular}

Note: Data on labor informality are from the Inter-American Development Bank. Data on GDP are from the International Monetary Fund. All data are annual.

Figure 2: Stylized Fact (iii) - Unemployment reacts less to GDP when informality is higher

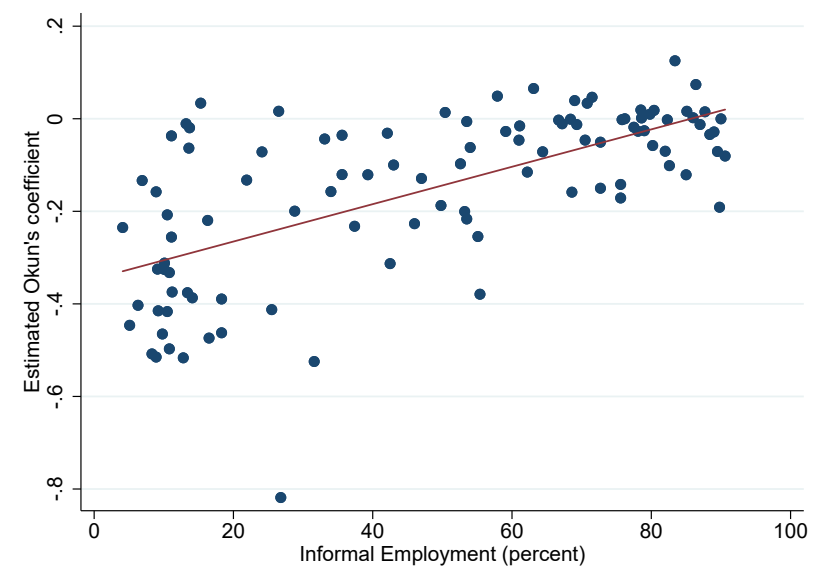

Note: Unemployment and informality data are from the International Labor Organization. To estimate the Okun's coefficient the change in unemployment is regressed on contemporaneous and one lag of GDP growth. 


\section{Model Overview}

The model includes a representative household that consumes and supplies labor, perfectly competitive intermediate good producers, a continuum of monopolistic competitive wholesale final good producers, retailers which aggregate wholesale final goods into a consumption bundle, and capital producers which invest to build new capital. Finally, there is a government sector which collects taxes and borrows to finance public expenditures and unemployment benefits, and a monetary authority which sets the short-term interest rate.

There are four types of goods: formal and informal domestically produced goods, imported goods, and a commodity. The informal good is only used for domestic household consumption. The formal good can be consumed domestically by households and the government, invested, or exported. The imported good can be consumed or invested. The economy receives a stochastic commodity endowment every period which is property of the government and is fully exported. Intermediate good producers use capital and labor to produce formal and informal intermediate inputs, which are sold to final good producers. Final good producers are monopolistic competitors that each produce a differentiated formal or informal good using the intermediate formal or informal inputs. The number of final good producers in each formal or informal sector is endogenous and depends on a sunk entry cost.

Perfectly competitive retailers combine the differentiated formal goods into an homogeneous formal good that is sold to households, capital producers, and the government, or exported to the rest of the world. Retailers do the same for the informal goods, but the homogeneous aggregate is only sold to households. Capital producers use imported and domestically produced formal goods to produce capital that they sell to the household, which in turn rents it to the intermediate good producers.

A detailed description of the full model can be found in Appendix A. In the remainder of this section we focus on a discussion of household preferences given their importance for our model relative to the literature. The representative household consumes a final consumption good $C_{t}$ which is defined as a CES aggregate of the domestically-produced good $C_{h, t}$ and the imported good $C_{f, t}$ :

$$
C_{t}=\left[\alpha_{c}^{\frac{1}{\eta_{c}}} C_{h, t} \frac{\eta_{c}-1}{\eta_{c}}+\left(1-\alpha_{c}\right)^{\frac{1}{\eta_{c}}} C_{f, t} \frac{\eta_{c}-1}{\eta_{c}}\right]^{\frac{\eta_{c}}{\eta_{c}-1}}
$$

where $\alpha_{c} \in[0,1]$ can be interpreted as a measure of home bias and $\eta_{c}>0$ is the elasticity of substitution between home and foreign produced goods. The total consumption cost is

$$
P_{t} C_{t}=P_{h, t} C_{h, t}+P_{f, t} C_{f, t} .
$$

The optimal intratemporal allocation between $C_{h, t}$ and $C_{f, t}$ implies that the domestic price level can be expressed as a composite of domestically-produced and imported good prices.

$$
P_{t}=\left[\alpha_{c} P_{h, t}^{1-\eta_{c}}+\left(1-\alpha_{c}\right) P_{f, t}^{1-\eta_{c}}\right]^{\frac{1}{1-\eta_{c}}} .
$$


while the demand functions are given by

$$
\begin{gathered}
C_{h, t}=\alpha_{c} p_{h, t}^{-\eta_{c}} C_{t} \\
C_{f, t}=\left(1-\alpha_{c}\right) p_{f, t}^{-\eta_{c}} C_{t}
\end{gathered}
$$

where $p_{s, t} \equiv P_{s, t} / P_{t}$, for $s=\{F, I, h, f\}$ is the price expressed in terms of final consumption. Total final consumption can be rewritten as

$$
C_{t}=p_{h, t} C_{h, t}+p_{f, t} C_{f, t}
$$

The domestic good $C_{h, t}$ is a composite of the formal good, $C_{F}$, and informal good, $C_{I}$, and takes the following form:

$$
C_{h, t}=C_{F, t}+\omega C_{I, t}^{\mu},
$$

The quasilinear function ensures a zero-income effect on the consumption of the informal good $C_{I, t}$ (Greenwood and Huffman, 1988). The formal and informal good are purchased at a price $p_{F, t}\left(p_{I, t}\right)$, expressed in terms of the final consumption good.

The total cost of domestic consumption is equal to

$$
p_{h, t} C_{h, t}=p_{F, t} C_{F, t}+p_{I, t} C_{I, t} .
$$

Intratemporal optimality conditions imply

$$
\mu \omega C_{I, t}^{\mu-1}=p_{I, t} / p_{F, t} .
$$

Notice that the substitution effect reduces the value of informal good expenditure as its price rises

$$
\frac{\partial\left(p_{I, t} C_{I, t}\right)}{\partial\left(p_{I, t} / p_{F, t}\right)}=-(\mu \omega)^{-1}\left(p_{I, t} / p_{F, t}\right)^{-1 /(1-\mu)}<0
$$

and the informal good expenditure share declines as total expenditure increases

$$
\frac{\partial\left(p_{I, t} C_{I, t} / p_{h, t} C_{h, t}\right)}{\partial\left(p_{h, t} C_{h, t}\right)}=-\frac{\mu}{1-\mu}(\mu \omega)^{-1} \frac{\left(p_{I, t} / p_{F, t}\right)^{-1 /(1-\mu)}}{\left(p_{h, t} C_{h, t}\right)^{2}}<0
$$

The latter yields the negative relationship between GDP per capita and informality which is at the heart of the paper. ${ }^{12}$

\footnotetext{
${ }^{12}$ There might of course be other mechanisms which could yield similar testable predictions at the macroeconomic level, but we are not aware of any that have been put forward in the literature.
} 


\section{Model Estimation}

\subsection{Steady-State Calibration}

Our first goal is to see how well the model matches the stylized facts presented in section 2 . We compare a large number of steady states to mimic the cross-country dimension. To anchor those exercises, we first calibrate the model to a representative Latin American economy - without lack of generality Colombia was chosen. We then change the values of a few key parameters in the model to obtain alternative steady states or 'countries'.

An overview of the baseline calibration is shown in Tables B1 and B2 in the Appendix. Table B1 lists the values of the model parameters set from values found in the literature, as well as the sources used. Table B2 presents target ratios used to calibrate parameters such as firm entry costs. Most elasticity and macro parameters are recovered from the literature, whenever possible from papers focused on Colombia, such as Gonzales et al. (2013). For the labor market parameters, we use values from related papers for Colombia or Latin America (such as Ulyssea (2018)'s estimates for bargaining power in Brazil) when available. This leaves us with six unknown parameters whose value is calibrated to match Colombia's labor market outcomes. The six parameters are the three TFP parameters (aggregate TFP, formal sector TFP and informal sector TFP) as well as the parameter determining the elasticity of substitution between formal and informal goods $(\mu)$ and the two hiring cost parameters $\left(\beta_{F}\right.$ and $\left.\beta_{I}\right)$. Due to the demand effect linking the level of GDP to informality, the TFP parameters play a very important role in this model.

Table 2 compares the empirical ratios to the ones obtained from the calibrated model. The steadystate matches the Colombian economy well. The three main labor market outcomes (labor informality, unemployment and formal to informal sector wages) are all closely matched as are major macro variables such as the share of informal output in total output, the investment-to-GDP ratio and the imports-to-GDP ratio.

\subsection{Simulated Method of Moments}

We use the simulated methods of moments (SMM) to estimate the parameters of the stochastic processes which best match business cycle moments in Colombia under the baseline calibration. Table 3 shows the resulting business cycle moments and compares them to the data: The top block reports the moments targeted by the SMM while the bottom block provides an assessment of the quality of calibration by comparing the simulated moments to the empirical moments of labor market variables not targeted by the SMM. Table B3 in the Appendix reports the corresponding parameter values. 
Table 2: Steady-State Model Fit

\begin{tabular}{cccc}
\hline \hline Variable & Variable Description & Data & Model \\
\hline$\frac{L_{I}}{L}$ & Informal employment as share of total employment & 0.55 & 0.51 \\
$\frac{W_{F}}{W_{I}}$ & Ratio of formal to informal sector wages & $1.3-1.6$ & 1.32 \\
$U$ & Unemployment rate & 0.13 & 0.13 \\
$\frac{p_{I} Y_{I}}{G D P}$ & Informal economy as share of GDP & around 0.42 & 0.38 \\
$\frac{p^{n n v} I}{G D P}$ & Private Investment as share of GDP & 0.23 & 0.23 \\
$\frac{p_{f} M}{G D P}$ & Imports as share of GDP & 0.22 & 0.26 \\
\hline \hline
\end{tabular}

Note: Data on the ratio of formal to informal wages in Colombia come from Daza and Gamboa (2013). Data on the share of the informal economy in total GDP are from Ulyssea (2018). Measuring labor informality is not a straightforward exercise and there is no unique number per country. The 0.55 reported in the table corresponds to ILO data which underlies Figure 1. The Colombia authorities report several numbers, depending on coverage (urban versus national) and the definition of informality, which are generally quite close to the ILO number. The ratio of formal-to-informal-sector wages is obtained by first controlling for observable characteristics given that there is no worker heterogeneity in the model.

Persistent TFP and commodity price shocks are key to matching the Colombian business cycle moments in our model. The resulting correlations between quarterly GDP growth and the growth of key GDP components (private consumption, public consumption and investment) match the data very closely. But the model-implied volatility of investment and GDP are higher than those in the data. This is due to a tension between matching the volatility of GDP and matching the volatility of unemployment and labor informality. Despite the presence of real wage rigidities and an explicit shock to firing probabilities in the model, highly persistent TFP shocks are necessary to match the volatility of unemployment, leading to excess volatility of GDP. The model is not able to fully resolve this tension and the result is that the volatility of GDP is somewhat too high while the volatility of unemployment is somewhat too low. The comparison of additional standard deviations and correlations not targeted by the SMM in the bottom six rows of table 3 is encouraging - most moments are adequately matched. ${ }^{13}$

\footnotetext{
${ }^{13}$ Although the SMM allows us to obtain parameter values in a more structured way, the results remain quite fragile.
} 
Table 3: Business Cycle Model Fit - Target Moments and Check for Additional Moments

\begin{tabular}{|c|c|c|c|}
\hline Target Moment & Moment Description & Data & Model \\
\hline Std. dev. of quarterly (real) GDP growth & $s d(\Delta \ln G D P)$ & 0.008 & 0.017 \\
\hline Std. dev. of quarterly priv. cons. growth & $s d(\Delta \ln C)$ & 0.006 & 0.005 \\
\hline Std. dev. of quarterly public cons. growth & $s d(\Delta \ln G)$ & 0.027 & 0.029 \\
\hline Std. dev. of quarterly investment growth & $s d(\Delta \ln I)$ & 0.035 & 0.070 \\
\hline Corr. priv. cons. growth and GDP growth & $\operatorname{corr}(\Delta \ln C, \Delta \ln G D P)$ & 0.659 & 0.634 \\
\hline Corr. public cons. growth and GDP growth & $\operatorname{corr}(\Delta \ln G, \Delta \ln G D P)$ & 0.366 & 0.227 \\
\hline Corr. investment growth and GDP growth & $\operatorname{corr}(\Delta \ln I, \Delta \ln G D P)$ & 0.295 & 0.269 \\
\hline Std. dev. unemployment rate & $s d(U)$ & 0.020 & 0.011 \\
\hline Std. dev. of informality rate (annual data) & $s d\left(\frac{L_{I}}{L}(\right.$ annual $\left.)\right)$ & 0.043 & 0.038 \\
\hline Moment & Moment Description & Data & Model \\
\hline Std. dev. of change in unemployment rate & $s d(\Delta U)$ & 0.004 & 0.002 \\
\hline Std. dev. of change in informality rate & $s d\left(\Delta \frac{L_{I}}{L}\right)$ & 0.005 & 0.010 \\
\hline Corr. change in unemployment rate and GDP growth & $\operatorname{corr}(\Delta U, \Delta \ln G D P)$ & -0.258 & -0.854 \\
\hline Std. dev. of change in informality rate (annual data) & $s d\left(\Delta \frac{L_{I}}{L}(\right.$ annual $\left.)\right)$ & 0.016 & 0.012 \\
\hline Corr. change in informality rate and GDP growth (annual data) & $\operatorname{corr}\left(\Delta \frac{L_{I}}{L}(\right.$ annual $), \Delta \ln G D P($ annual $\left.)\right)$ & -0.748 & -0.846 \\
\hline Corr. change in unempl. rate and change in informality rate (annual data) & $\operatorname{corr}\left(\Delta \frac{L_{I}}{L}(\right.$ annual $), \Delta U($ annual $\left.)\right)$ & 0.728 & 0.844 \\
\hline
\end{tabular}

Note: Since informality data is of higher quality at the annual frequency we report the correlations involving labor informality using annualized data (both in the model and the empirical data). 


\section{Results}

\subsection{Matching the Stylized Facts}

Starting from the baseline calibration we change formal sector TFP along a large grid, conditional on a set of values for labor market frictions (tax rate, hiring cost parameter and firm entry costs) to obtain alternative steady states. Figure 3 plots the resulting relationship between labor informality and per capita GDP from the model and compares it to the relationship in the data. ${ }^{14}$ The model does remarkably well in matching the negative, convex relationship for levels of labor informality between roughly 60 and 20 percent corresponding to per capita GDP between USD 10,000 and USD 50,000. The model struggles to generate informality ratios above 70 percent for the poorest countries in the World, with per capita GDP below USD 5,000, but the slope of the quadratic fit matches the data well even in that region. ${ }^{15}$

Formal sector TFP $\left(\theta_{F}\right)$ is the key model parameter which allows to match the shape of the curve. Simply increasing and decreasing economy-wide TFP $\left(\theta_{a}\right)$ creates a slope that is too 'flat': Informality does not fall as fast as per capita GDP increases. This result sheds light on the role of TFP in the decline in informality as countries get richer. Rather than the simultaneous increase in both formal and informal sector TFP, it is the growing gap between formal and informal sector TFP as the former grows and the latter stagnates that drives the reduction in labor informality in richer countries. This observation is consistent with the analysis in La Porta and Shleifer (2014) which sees economic growth as being driven by the formal sector - "firms run by educated entrepreneurs and exhibiting much higher levels of productivity" - which leads to the relative and eventually absolute decline of the informal sector.

The role of labor market frictions is also relatively limited compared to that of formal sector TFP. We return to this issue below.

While stylized fact (i) highlighted a cross-country relationship between informality and per capita GDP in the steady state, stylized facts (ii) and (iii) capture features of labor informality at the business cycle frequency. For each of 'country' or steady state derived above, we simulate the model over 49 periods using the stochastic processes recovered through the SMM estimation in section 5.3. ${ }^{16}$ One clear shortcoming is that the stochastic parameters were chosen to best match business cycle moments for Colombia and the shock processes might vary by country. But given that we want to simulate business cycles for a large set of steady-states/countries, it is impractical to re-estimate a full set of stochastic processes for each of them. We use the simulation results to

\footnotetext{
${ }^{14}$ The model assumes a measure 1 of workers which equals the total measure of households. As such per capita GDP and GDP are equivalent in the model.

${ }^{15}$ We map per capita GDP in the model to per capita GDP expressed in 2011 PPP USD using the ratio of GDP in the model for the baseline calibration to Colombian per capita GDP data.

${ }^{16} 49$ corresponds to the number of observations we used to compute business cycle and labor market moments for Colombia.
} 
Figure 3: Stylized Fact (i): Data (Left-Hand-Side) versus Model (Right-Hand Side)
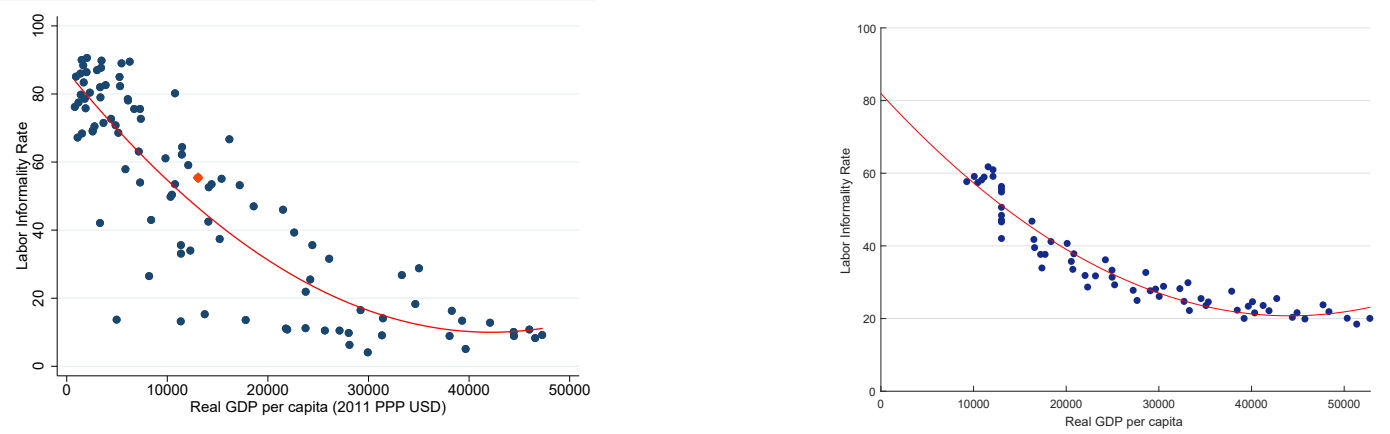

Note: Informality data are from the International Labor Organization in panel (a). Panel (b) shows steady state outcomes generated by varying formal sector TFP as well as labor market frictions around the calibrated reference point (Colombia) represented as an orange diamond. 
calculate the correlation between the change in (log) GDP and the change in the labor informality rate (stylized fact ii) and run a simple regression of unemployment on GDP growth to recover the Okun's coefficient (stylized fact iii) for each of the steady states.

With regard to stylized fact (ii), the correlation of the change in the informality rate and GDP growth has the correct sign but is higher in the model simulations than in the data. In the model the correlation of the change in informality and GDP growth is larger in absolute value than -0.6 in each of the steady states which we use to proxy Latin American economies (the average is -0.81) whereas the empirical correlation is only -0.4 on average in the three Latin American countries for which we have harmonized data. This may not be entirely surprising though since the model was calibrated using data for Colombia only. And the model matches the Colombian data well (-0.75 in the data versus -0.85 in the model, see Table 4 ).

Table 4: Stylized Fact (ii): Data versus Model

\begin{tabular}{lllll}
\hline \hline & \multicolumn{1}{l}{ Corr. $\left(\ln \Delta G D P, \Delta L_{I} / L\right)$} & \multicolumn{2}{l}{ Corr. $\left(\ln G D P, L_{I} / L\right)$} \\
\hline & Data & Model & Data & Model \\
& & & & \\
Average of Latin American economies & -0.4 & -0.81 & -0.96 & -0.98 \\
Colombia & -0.75 & -0.85 & -0.95 & -0.99 \\
\hline \hline
\end{tabular}

Note: Data on labor informality are from the Inter-American Development Bank. Data on GDP are from the International Monetary Fund. All data are annual. In the data, the average for Latin American economies corresponds to the average of Brazil, Colombia and Peru as presented in the stylized facts section above. In the model, the average of Latin American economies corresponds to the average of the baseline calibration (Colombia) and 16 other steady states with similar levels of informality.

Finally Figure 4 plots estimated Okun's law coefficients against steady state labor informality from the data and the model. In the case of the model, the Okun's coefficients are estimated from simulated business cycles starting from different steady states, but using the same stochastic processes. Nevertheless, the model does well, both in terms of the average level of the Okun's coefficient and in terms of the slope of the relationship with labor informality. As noted before, the model does not cover the full empirical support of the labor informality distribution but is restricted to the range of 20 to 65 percent. Yet the relationship between the estimated Okun's coefficient and labor informality is upward sloping in the model just as in the data: The higher the level of informality, the stronger the informality-formality margin relative to the employmentunemployment margin. Quantitatively, the slope and intercept of the fitted lines are nearly identical in the data and the model. 
Figure 4: Stylized Fact (iii): Data (Left-Hand-Side) versus Model (Right-Hand Side)
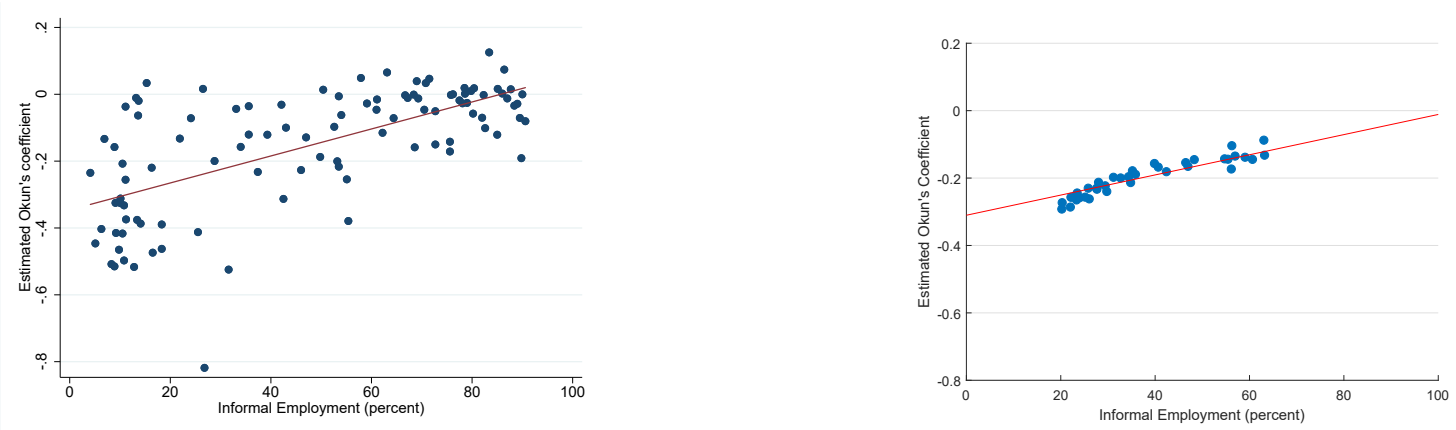

Note: Unemployment and informality data are from the International Labor Organization. To estimate the Okun's coefficient the change in unemployment is regressed on contemporaneous and one lag of GDP growth, both in the empirical data and the model-generated data. 


\subsection{The Role of Structural Reforms for Labor Market Outcomes}

Given the model's ability to match the stylized facts it was set out to capture (with all the caveats that apply), we can use it to investigate the role labor market reforms could play for unemployment and informality in Colombia.

In 2012, Colombia reduced the payroll tax from 29.5 to 16 percent. Several papers have subsequently studied the impact of the reform on labor informality and have concluded that it resulted in a reduction of 2-3 percentage points (see, for example, Fernandez and Villar (2017)). We can compare those empirically estimated numbers with the model predictions of the expected impact. The model results show that increasing payroll taxes from 16 to 29.5 percent (the reverse of the actual reform given that our baseline calibration has a tax rate of 16 percent) would increase labor informality by close to 4 percentage points, somewhat above the empirical estimates. At the same time, the model also suggests that the unemployment rate fell by 1 percentage point as a consequence of the 2012 reform (we are not aware of an empirical estimate to compare this to).

To study the effect of broader labor market reforms, as well as to return to the role of higher TFP alluded to in the discussion of stylized fact (i) above, we compare the steady state for two additional calibrations: one which has all the same parameters as the baseline except lower formal sector frictions (lower firm entry costs, lower labor tax and lower hiring costs, although those frictions remain of course higher in the formal than in the informal sector), and a second one which simply has higher formal sector TFP (given the importance of the parameter for matching the cross-country data). We thus obtain three steady states: (a) Colombia, (b) Colombia with flexible labor market, and (c) Colombia with higher formal sector TFP. We set the change in TFP in (c) such that the steady state labor informality rate in (b) and (c) are the same. The changes relative to the baseline are large: (b) cuts all formal sector frictions by half, while (c) increases formal sector TFP by 25 percent.

Table 5 reports key variables for the three steady states. The results show that a broad labor market reform does have the potential to substantially change the level of labor informality and unemployment. The impact on informality is both direct, by reducing the wedge between the formal and informal sector, and indirect - by making the economy richer, the demand effect induces an additional fall in informality. The level of informality still remains high at 41 percent even following what amounts to drastic reform. On the other hand, an increase of 25 percent in formal sector TFP reduces labor informality through the demand channel only (notice the higher level of real GDP in (c)) and leads to the same level of informality as the labor market reforms in (b). This highlights again the interaction between income level and informality, as previously discussed. However, unemployment (the second margin of labor market adjustment in the model) shows a rather different picture. The flexible economy has lower unemployment than the baseline economy as expected. But the rich economy does not experience any reduction in unemployment relative to

baseline. This is consistent with a lack of clear cross-country association between GDP per capita 
and the unemployment rate (the empirical correlation is -0.1). Based on the model results, both labor market reform and productivity gains have a role to play in reducing informality, albeit the latter seems to be the dominant force. Labor market reform is key for lowering unemployment, however.

Table 5: Steady-State - Baseline Economy vs. Low Frictions vs. High TFP

\begin{tabular}{ccccc}
\hline \hline Variable & Variable Description & (a) Baseline & (b) Low Frictions & (c) High Formal Sector TFP \\
\hline$R G D P$ & Real GDP & 0.71 & 0.84 & 0.92 \\
$U$ & Unemployment Rate & 0.13 & 0.1 & 0.13 \\
$\frac{L_{I}}{L}$ & Labor Informality & 0.51 & 0.41 & 0.41 \\
$\frac{p_{I} Y_{I}}{G D P}$ & Output Informality & 0.39 & 0.28 & 0.25 \\
$\frac{W_{F}}{W_{I}}$ & Formal to Informal Wages & 1.31 & 1.49 & 1.68 \\
\hline \hline
\end{tabular}

Note: Baseline corresponds to the calibration as presented in Section 4.1. Starting from the baseline calibration Low Frictions shows the steady state when entry costs in the formal sector, the payroll tax rate and the hiring cost parameter in the formal sector are cut in half. For entry costs, given that the parameter is calibrated to match a target ratio, the change is approximate. Starting from the baseline calibration High Formal TFP shows the steady state when formal sector TFP is increased by 25 percent. 


\subsection{Business Cycle Dynamics}

Inspecting the impulse response functions to a TFP and commodity price shock helps to understand the mechanics of the model. In both cases we focus on the reaction of the formal and informal labor market to shocks with high persistence (see Table B3). To gain additional insights we also compare the baseline economy with the above discussed case of a flexible labor market and with a rich economy case. As previously mentioned, for comparability, the informality share of employment is set to be the same across calibrations (2) and (3). Note, however, that steady state output informality is the lowest in the rich economy (Table 5).

\section{TFP shock}

A positive one-standard-deviation TFP shock (i.e., a 2 percent increase in TFP) that equally affects both the formal and informal sector boosts GDP growth and stimulates consumption, investment, and exports in all three economies. The impact is similar across calibrations but slightly stronger for the rich and flexible economies as the formal sector, which is more capital intensive, can better exploit higher productivity, reflected in relatively higher exports. The fall in unemployment is also stronger in the rich and flexible economies. Not surprisingly, inflation declines mildly and unemployment falls as hiring in the formal sector increases, triggering a monetary policy reaction. The higher income levels induce a change in preferences towards the formal good whose demand also benefits from higher investment and exports. Thus, factors of production reallocate toward the formal sector which increases its relative share in both employment and value added. Finally (not shown), the shock also induces an improvement in the fiscal balance as the payroll tax base expands, allowing for a cut in the distortionary payroll tax rate. The fall in labor market informality and in the informality share of value added is the strongest under the baseline calibration. This is not surprising since the economy starts from a relatively higher level of informality. Similarly, the fall in unemployment is smaller reflecting the countercyclical nature of the informal sector which shrinks during periods of boom. Since all responses are symmetric, a higher level of informality, ceteris paribus and conditional to TFP shocks, mitigates business cycle fluctuations in GDP and, especially, in consumption and unemployment. This is an important consideration given that higher levels of informality are also associated with a less sizable welfare state.

\section{Commodity price shock}

A positive one-standard-deviation commodity terms of trade shocks (i.e., a 10 percent increase in the commodity price) has some similarities with the TFP shock as it boosts GDP, consumption, and investment. However, the positive wealth effect appreciates the exchange rate and the (noncommodity) export volume declines. The higher income, however, induces an increase in household demand for domestic goods, but more so for the formal goods. Coupled with an increase in investment (and notwithstanding the decline in export demand), value added and employment in the formal sector expand relatively more. Hence, the informal share in both value added and employment declines in the three economies. Also, the cost of imported goods declines, increasing 
the competitiveness of the formal sector vis-à-vis the informal sector. ${ }^{17}$ The difference between the three economies is less pronounced than following a TFP shock, and the impact on the informality share is smaller, which in part is due to the different behavior of the (non-commodity) export sector. As before, the reduction in unemployment is the smallest for the baseline calibration because the behavior of the informal sector is, once again, counter-cyclical also conditional to a commodity price shock. Interestingly, the fall in unemployment is not high enough to compensate for the initial reduction in inflation which triggers an interest rate cut.

\footnotetext{
${ }^{17}$ Quantitatively, a temporary but persistent positive shock of close to 10 percent in commodity export prices is estimated to increase the level of real GDP by 0.6 percent for over 20 quarters, driven by a sharp short term increase in investment of over 6 percent and a more persistent but much smaller increase in consumption. Non-resource exports fall by around 1 percent but recover in the medium-term.
} 
Figure 5: Reaction to Positive TFP Shock
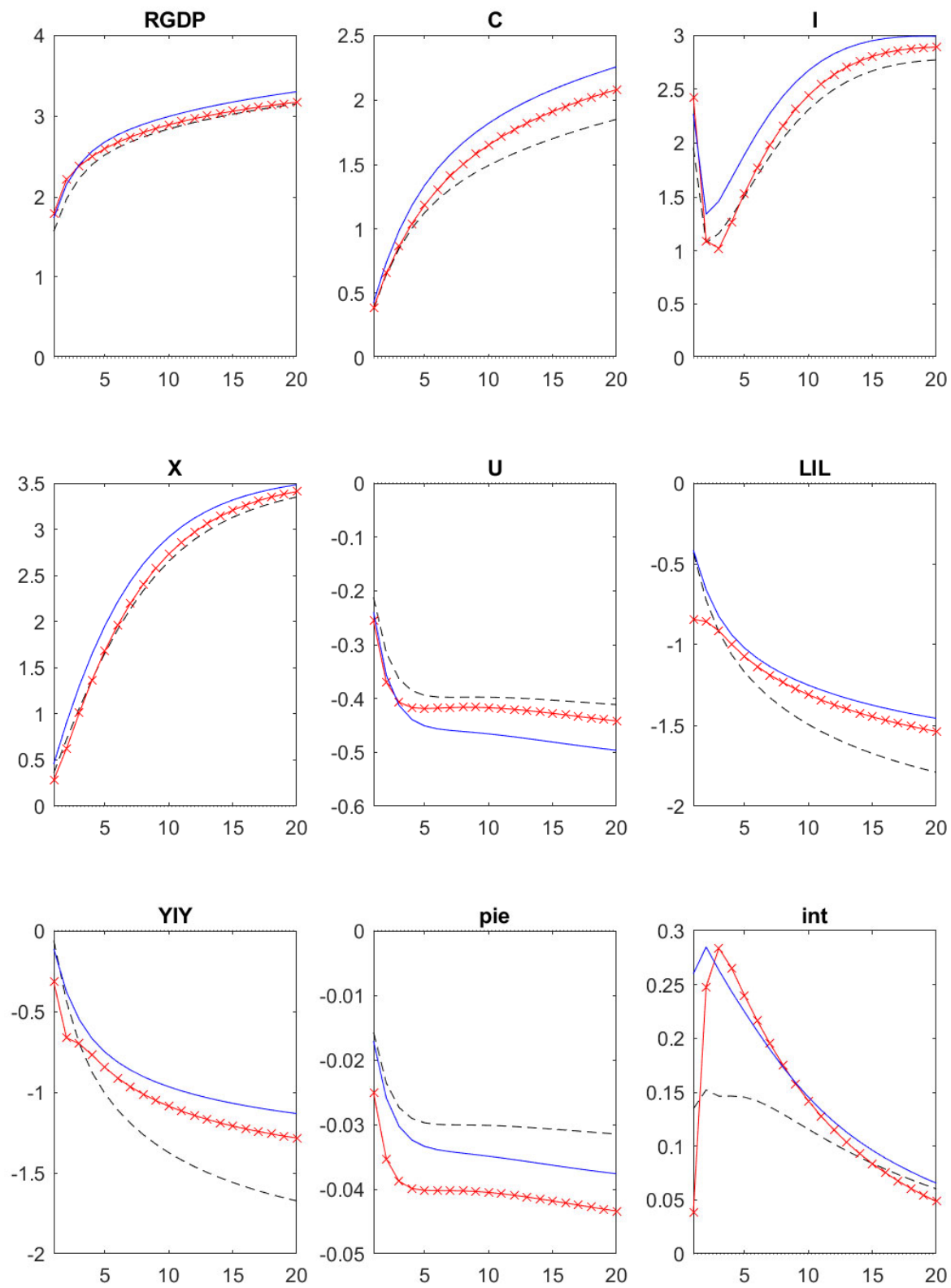

----- baseline economy $\_x$ flexible labor market economy — rich economy 
Figure 6: Reaction to Positive Commodity Price Shock
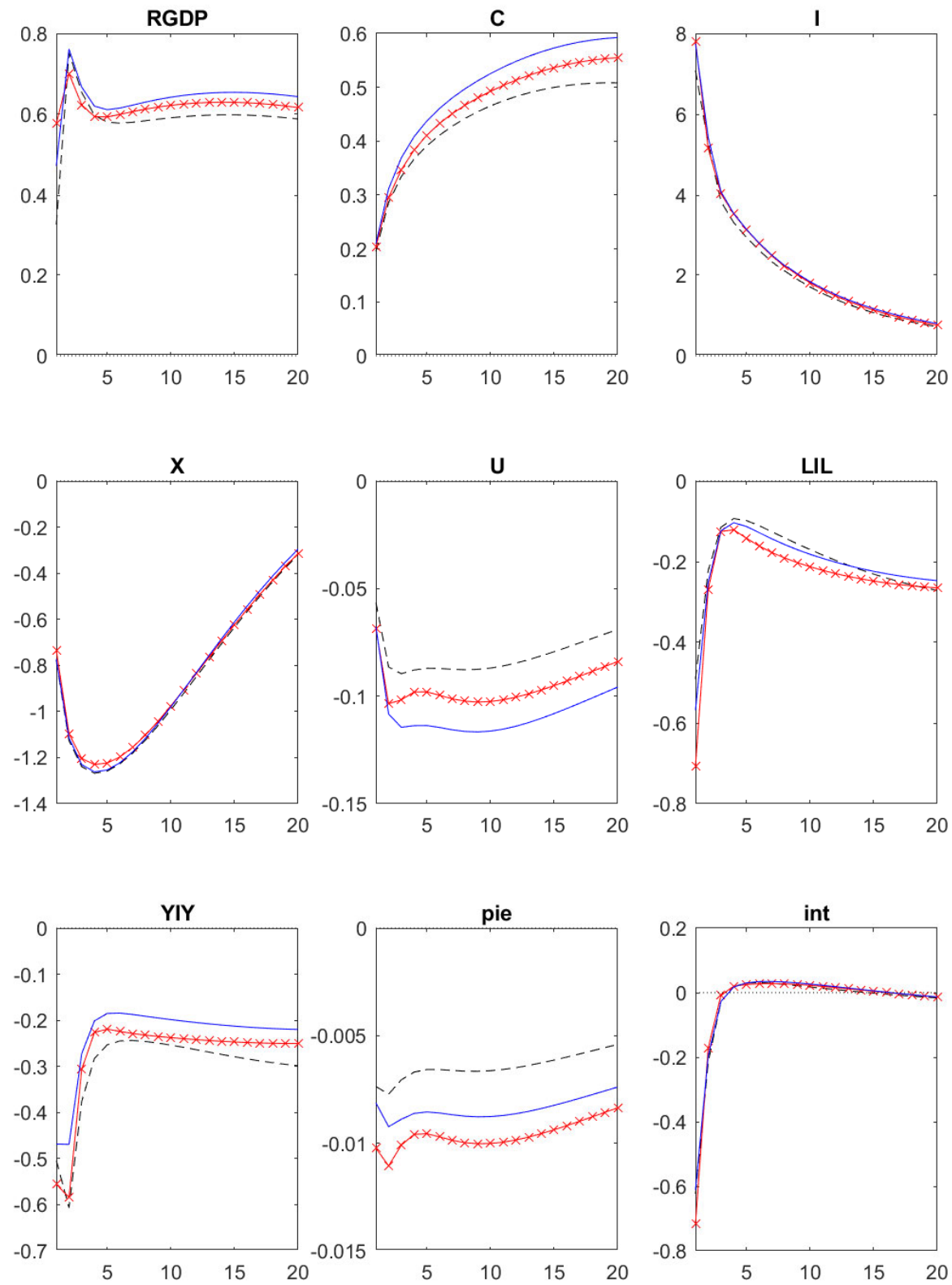

----- baseline economy $\_x$ flexible labor market economy —— rich economy 


\section{Conclusion}

In this paper we presented a dynamic stochastic general equilibrium model which can replicate key stylized facts about the relationship between the informality rate, the unemployment rate, and GDP, both across countries and over the business cycle. The model is calibrated to match features of the Colombian economy. We show that a 50 percent reduction in all labor market frictions is necessary to achieve the same reduction in labor informality as that obtained by a 25 percent increase in labor productivity in the formal sector, highlighting that while both channels are important, reductions in informality will always be bounded absent productivity gains. On the other hand, higher formal sector labor productivity has no direct impact on the unemployment rate while labor market reform to reduce frictions is key in that regard. Over the business cycle informality acts as an important shock absorber, limiting fluctuations in unemployment and macroeconomic aggregates.

Future work could refine the modeling of the government sector to allow for a more nuanced look of how different fiscal policy tools affect outcomes. On the monetary policy side, the model results suggest that economies with higher informality may need to move the policy rate less as growth, unemployment, and inflation react less to shocks. Future work could explore whether the way informality is specified in the model has an important bearing on this result or whether it holds up in different specifications. Overall, we see our attempt as an initial step to incorporating informality

more rigorously in standard macro-economic models used for policy making across governments and central banks in emerging markets. 


\section{References}

Andrew B. Abel. Asset prices under habit formation and catching up with the Joneses. American Economic Review, 80(2):38-42, May 1990.

Rahul Anand and Purva Khera. Macroeconomics impact of product and labor market reforms on informality and unemployment in India. IMF Working Paper, WP/16/47, 2016.

Olivier Blanchard and Jordi Gali. Labor markets and monetary policy: A new keynesian model with unemployment. American Economic Journal: Macroeconomics, 2(2):1-30, April 2010.

Mariano Bosch and Julen Esteban-Pretel. Job creation and job destruction in the presence of informal markets. Journal of Development Economics, 98(2):270 - 286, 2012.

Mariano Bosch and William Maloney. Cyclical movements in unemployment and informality in developing countries. IZA Discussion Paper Series, No. 3514, May 2008.

Paul B. Castillo and Carlo Montoro. Dinmica inflacionaria en presencia de informalidad en mercados laborales*. Economia Chilena, 15(1):33 - 47, April 2012.

Antonio David, Frederic Lambert, and Frederik Toscani. More work to do? taking stock of Latin American labor markets. IMF Working Paper, WP/19/55, March 2019.

Nancy Daza and Luis Fernando Gamboa. Informal-formal wage gaps in colombia. ECINEQ Working Paper Series, WP 2013-301, August 2013.

Andres Fernandez, Andres Gonzalez, and Diego Rodriguez. Sharing a ride on the commodities roller coaster: Common factors in business cycles of emerging economies. Journal of International Economics, 111:99 - 121, 2018. ISSN 0022-1996.

C. Fernandez and L.. Villar. The impact of lowering the payroll tax on informality in colombia. Economa, 18(1):125-155, 2017.

Andres Gonzales, Martha Lopez, Norberto Rodriguez, and Santiago Tellez. Fiscal policy in a small open economy with oil sector and non-ricardian agents. Banco de la Republica Borradores de Economia, Num. 759, 2013.

Zvi Hercowitz Greenwood, Jeremy and Gregory W. Huffman. Investment, capacity utilization, and the real business cycle. American Economic Review, 78(3):402-417, June 1988.

ILO. Women and men in the informal economy: A statistical picture. Technical report, ILO, 2018.

Rafael La Porta and Andrei Shleifer. Informality and development. Journal of Economic Perspectives, 28(3):109-126, Summer 2014. 
Gustavo Leyva and Carlos Urrutia. Informality, labor regulation, and the business cycle. Journal of International Economics, 126, 2020.

Norman V. Loayza. Informality in the process of development and growth. The World Economy, 39(12):1856-1916, 2016.

Giovanni Lombardo and David Vestin. Welfare implications of calvo vs. rotemberg-pricing assumptions. Economics Letters, 100:275-279, 2008.

Costas Meghir, Renata Narita, and Jean-Marc Robin. Wages and informality in developing countries. American Economic Review, 105(4):1509-46, April 2015.

Zsuzsa Munkacsi and Magnus Saxegaard. Structural reform packages, sequencing, and the informal economy. IMF Working Paper, WP/17/125, 2017.

Guillermo E. Perry, William F. Maloney, Omar S. Arias, Pablo Fajnzylber, Andrew D. Mason, and Jaime Saavedra-Chanduvi. Informality: Exit and exclusion. Technical report, Latin American and Caribbean Studies. Washington, DC: World Bank, 2007.

James E. Rauch. Modelling the informal sector formally. Journal of Development Economics, 35 (1):33 - 47, 1991.

Paulina Restrepo-Echavarria. Macroeconomic volatility: The role of the informal economy. European Economic Review, 70:454 - 469, 2014.

Julio J. Rotemberg. Sticky prices in the United States. Journal of Political Economy, 90(6): 1187-1211, December 1982.

Frank Smets and Rafael Wouters. Shocks and frictions in us business cycles: A bayesian dsge approach. American economic review, 97:586-606, 2007.

Stephen J. Turnovsky. Domestic and foreign disturbances in an optimizing model of exchange-rate determination. Journal of International Money and Finance, 4(1):151-171, 1985.

Gabriel Ulyssea. Regulation of entry, labor market institutions and the informal sector. Journal of Development Economics, 91(1):87 - 99, 2010.

Gabriel Ulyssea. Firms, informality, and development: Theory and evidence from brazil. American Economic Review, 108(8):2015-47, August 2018. 


\section{Appendices}

\section{A Model Description}

\section{A.1 Household}

The representative household is made up of a continuum of members represented by the unit interval. Household members can supply formal, $L_{F}$, and informal $L_{I}$ labor. Each period, the representative household receives labor income, profits from final good producers, capital income from renting capital to intermediate good producers, interest income from domestic and foreign bond holdings, and income from selling the depreciated capital stock to capital good producers. It uses this income to consume and save in the form of domestic and foreign bonds (denominated in foreign currency) and new capital bought from capital good producers, and to invest in start-up firms. Formally, the representative household maximizes the expected discounted lifetime utility of consumption:

$$
E_{0} \sum_{t=0}^{\infty} \beta^{t}\left(\zeta_{C, t}(1-h) \ln \left(C_{t}-h C_{t-1}\right)-v\left(L_{F, t}, L_{I, t}\right)\right)
$$

subject to a budget constraint, where $C_{t}$ denotes consumption; the discount factor $\beta$ and the external habit persistence parameter $h$ both lie between 0 and $1 ;^{18} \zeta_{C, t}$ is a consumption preference shock; and the function $v(.,$.$) captures the disutility from working.$

\section{A.1.1 Labor supply}

The labor supply requires that the mass of both formal and informal employed members is bounded $0<L_{s, t} \leq 1$, for $s=F, I$; while $L_{t}=L_{F, t}+L_{I, t}$ is the total fraction of members employed satisfying $0<L_{t} \leq 1$. Labor force has, thus, been normalized to 1. Following Blanchard and Gali (2010), we assume

$$
v\left(L_{F, t}, L_{I, t}\right)=\xi_{F} L_{F, t}^{1+\lambda_{F}} /\left(1+\lambda_{F}\right)+\xi_{I} L_{I, t}^{1+\lambda_{I}} /\left(1+\lambda_{I}\right)
$$

where we allow for a different disutility of labor between formal and informal jobs.

There is no job search cost for the household members, however, frictions on the hiring side will result in a share of household members to be unemployed and a flow of household members entering and exiting jobs in each period. ${ }^{19}$ End-of-period unemployment $U_{t}$ is, thus, equal to $1-L_{F, t}-L_{I, t}$.

\footnotetext{
${ }^{18}$ We are considering a "catching up with the Joneses" utility function as in Abel (1990), so that the household does not take into account the effect of current consumption decisions on the habit stock.

${ }^{19}$ Household members are insured against labor income shocks which guarantees the same consumption level across all household members regardless of their employment status.
} 
Employed individuals earn a wage $W_{F, t}$ in the formal sector, which is subject to labor income tax $\tau_{F}$, and a wage $W_{I, t}$ in the informal sector. Unemployed individuals receive an unemployment benefit $W_{U, t}$. The wage is Nash bargained with intermediate good firms. The marginal rate of substitution between working in sector $s$ and consuming for the representative household is given by:

$$
M R S_{s, t}=\xi_{s} L_{s, t}^{\lambda} \frac{\left(C_{t}-h C_{t-1}\right)}{\zeta_{C, t}(1-h)}, \quad s \in(F, I)
$$

\section{A.1.2 Preferences}

The final consumption good $C_{t}$ is defined as a CES aggregate of the domestically-produced good $C_{h, t}$ and the imported good $C_{f, t}$ :

$$
C_{t}=\left[\alpha_{c}^{\frac{1}{\eta_{c}}} C_{h, t} \frac{\eta_{c}-1}{\eta_{c}}+\left(1-\alpha_{c}\right)^{\frac{1}{\eta_{c}}} C_{f, t} \frac{\eta_{c}-1}{\eta_{c}}\right]^{\frac{\eta_{c}}{\eta_{c}-1}}
$$

where $\alpha_{c} \in[0,1]$ can be interpreted as a measure of home bias and $\eta_{c}>0$ is the elasticity of substitution between home and foreign produced goods.

The demand functions are given by

$$
\begin{gathered}
C_{h, t}=\alpha_{c} p_{h, t}^{-\eta_{c}} C_{t} \\
C_{f, t}=\left(1-\alpha_{c}\right) p_{f, t}^{-\eta_{c}} C_{t}
\end{gathered}
$$

where $p_{s, t} \equiv P_{s, t} / P_{t}$, for $s=\{F, I, h, f\}$ is the price expressed in terms of final consumption. Total final consumption can be rewritten as

$$
C_{t}=p_{h, t} C_{h, t}+p_{f, t} C_{f, t}
$$

The domestic good $C_{h, t}$ is a composite of the formal good, $C_{F}$, and informal good, $C_{I}$, and takes the following form:

$$
C_{h, t}=C_{F, t}+\omega C_{I, t}^{\mu},
$$

The total cost of domestic consumption is equal to

$$
p_{h, t} C_{h, t}=p_{F, t} C_{F, t}+p_{I, t} C_{I, t} .
$$

Intratemporal optimality conditions imply

$$
\mu \omega C_{I, t}^{\mu-1}=p_{I, t} / p_{F, t} .
$$




\section{A.1.3 Financial and physical capital investment}

Households can invest in inflation-protected domestic bonds issued by the government, $B$, and international bonds $B^{*}$ denominated in foreign currency. The real exchange rate is defined as $\Xi_{t}=e_{t} \frac{P_{t}^{*}}{P_{t}}$ where $e_{t}$ is the nominal exchange rate and $P_{t}^{*}$ is the price of foreign consumption. Financial wealth at the beginning of period is $\left(1+r_{t-1}\right) B_{t-1}+\Xi_{t}\left(1+r_{t-1}^{*}\right) B_{t-1}^{*}$ where $r_{t}$ is the domestic real interest rate and $r_{t}^{*}$ is the real interest rate at which the household borrows or lends foreign currency funds converted in real local currency at the rate $\Xi_{t}$.

$$
1+r_{t}=E_{t}\left[\frac{1+i_{t}}{\pi_{t+1}}\right]
$$

where $\pi_{t}=P_{t} / P_{t-1}$ denotes inflation in period $t$ and $i_{t}$ is the domestic nominal interest rate.

Following Turnovsky (1985), we assume the household pays a transaction cost when trading in the foreign currency bond. The intermediation cost depends on the holdings of net foreign assets as a ratio to GDP.

$$
\varphi\left(B_{t}^{*}\right)=\exp \left(\varphi_{B^{*}} \Xi_{t} B_{t}^{*} / G D P_{t}\right)
$$

We define

$$
H_{B, t}=-B_{t}-\Xi_{t} \varphi\left(B_{t}^{*}\right) B_{t}^{*}+\left(1+r_{t-1}\right) B_{t-1}+\Xi_{t}\left(1+r_{t-1}^{*}\right) B_{t-1}^{*} .
$$

The beginning of period capital stock, $K_{t-1}$, is rented at a (real) rate $R_{t}^{k}$ to intermediate good producers in period $t$ and then sold depreciated at a rate $\delta_{k}$ at the end of the period to capital producers for a price $Q_{t}$, expressed in final consumption. Since the investment bundle is in general different from the consumption bundle, the real price of capital, $Q$, is not one in the steady state.

\section{A.1.4 Entry costs and corporate Profits}

The household owns all the firms in the economy. Retailers and capital producers are competitive and thus have zero profits, but intermediate good and final good producers have positive profits in steady state. Hiring frictions give intermediate firms positive profits, $\Pi_{s, t}^{i} \geq 0$, while final good wholesale producers enjoy monopolistic competition profits, $\Pi_{s, t}^{f} \geq 0$. The household bears the cost of starting new monopolistic (formal and informal) wholesalers. The entry costs $\frac{P_{F, t}}{P_{t}} E C_{F} \geq 0$ and $\frac{P_{I, t}}{P_{t}} E C_{I} \geq 0$ are expressed in terms of the final consumption good. The total profit from intermediate firms and cash flow from wholesalers is

$$
H_{P, t}=\sum_{s \in F, I}\left[\Pi_{s, t}^{i}+\left(\Pi_{s, t}^{f}-p_{s, t} E C_{s} N_{s, t}^{e}\right)\right]
$$

where $N_{F, t}^{e}$ and $N_{I, t}^{e}$ denote the number of new final good producers (entrants) in the formal and informal sector respectively, while $N_{F, t}$ and $N_{I, t}$ are the numbers of installed final good firms in each sector. 


\section{A.1.5 Budget constraint and equilibrium conditions}

The household's budget constraint can be written as:

$C_{t}+Q_{t} K_{t}+T_{t}=R_{t}^{k} K_{t-1}+Q_{t}\left(1-\delta_{k}\right) K_{t-1}+H_{B, t}+H_{P, t}+\left(1-\tau_{F}\right) W_{F, t} L_{F, t}+W_{I, t} L_{I, t}+W_{U, t} U_{t}$ where $T_{t}$ is a lump-sum tax.

The first order conditions with respect to $C_{t}, K_{t}, B_{t}$, and $B_{t}^{*}$ yield:

$$
\begin{aligned}
& 1=E_{t}\left[\rho_{t, t+1} \frac{R_{t+1}^{k}+\left(1-\delta_{k}\right) Q_{t+1}}{Q_{t}}\right] \quad \text { (capital pricing) } \\
& 1=E_{t}\left[\rho_{t, t+1}\left(1+r_{t}\right)\right] \\
& 1=E_{t}\left[\rho_{t, t+1} \frac{\Xi_{t+1}}{\Xi_{t}} \frac{\left(1+r_{t}^{*}\right)}{\varphi\left(B_{t}^{*}\right)\left(1+\varphi_{B^{*}} \Xi_{t} \frac{B_{t}^{*}}{G D P_{t}}\right)}\right] \quad \text { (foreign currency bond pricing) }
\end{aligned}
$$

where

$$
\rho_{t, t+1}=\beta\left(\frac{\zeta_{C, t+1}}{\zeta_{C, t}}\right)\left(\frac{C_{t}-h C_{t-1}}{C_{t+1}-h C_{t}}\right) .
$$

Equations (11) and (12) imply the uncovered interest parity.

\section{A.2 Intermediate good producers}

Intermediate good producers in the formal and informal sectors are perfectly competitive firms producing intermediate formal and informal goods, $Z_{F, t}$ and $Z_{I, t}$, by combining capital and labor via a Cobb-Douglas function with possibly different capital elasticities, $\psi_{F}$ and $\psi_{I}$, aggregate total factor productivity $\theta_{a, t}$, and sector-specific productivities $\theta_{F, t}$ and $\theta_{I, t}$ :

$$
Z_{s, t}=\theta_{a, t} \theta_{s, t} K_{s, t}^{\psi_{s}} L_{s, t}^{1-\psi_{s}}, \quad s \in(F, I)
$$

Part of that output is used to pay for hiring costs $H C_{s, t}$ when the firms hire new labor $H_{s, t}$. As in Blanchard and Gali (2010), hiring costs are an increasing function of labor market tightness $x_{t} \equiv \sum_{s} H_{s, t} / U_{t}$ where $U_{t}$ denotes unemployment:

$$
H C_{s, t}=\beta_{h, s} x_{t}^{\alpha_{h, s}}
$$

The profit function of intermediate good producers in each sector is therefore:

$$
\Pi_{s, t}^{i}=p_{s, t}^{z}\left(Z_{s, t}-H C_{s, t} H_{s, t}\right)-W_{s, t} L_{s, t}-R_{t}^{k} K_{s, t}, \quad s \in(F, I) .
$$


where $p_{s, t}^{z}=\frac{P_{s, t}^{z}}{P_{t}}$. The number of people employed in each sector varies depending on firms' endogenous hiring decisions and on a sector-specific, time-varying, probability of firing $\sigma_{s, t}$. Given the linear hiring cost, there is no incentive for labor hoarding.

Employment in each sector follows the law of motion:

$$
L_{s, t}=\left(1-\sigma_{s, t}\right) L_{s, t-1}+H_{s, t}, \quad s \in(F, I) .
$$

Intermediate good firms in each sector choose $\left\{K_{s, t+i}, L_{s, t+i}\right\}_{i=0}^{\infty}$ to maximize the expected discounted value of current and future profits:

$$
E_{t} \sum_{i=0}^{\infty} \rho_{t, t+i} \Pi_{s, t+i}^{i}
$$

where $\rho_{t, t+i}=\beta^{i}\left(\frac{\zeta_{C, t+i}}{\zeta_{C, t}}\right)\left(\frac{C_{t}-h C_{t-i}}{C_{t+i}-h C_{t}}\right)$ is the stochastic discount factor. The first order conditions are:

$$
\begin{aligned}
R_{t}^{k} & =p_{s, t}^{z} \psi_{s} \frac{Z_{s, t}}{K_{s, t}}, \quad s \in(F, I) \\
W_{s, t} & =p_{s, t}^{z}\left(1-\psi_{s}\right) \frac{Z_{s, t}}{L_{s, t}}-p_{s, t}^{z} H C_{s, t}+E_{t}\left[\rho_{t, t+1} p_{s, t+1}^{z} H C_{s, t+1}\left(1-\sigma_{s, t+1}\right)\right], \quad s \in(F, I) .
\end{aligned}
$$

As the rental cost of capital $R_{t}^{k}$ is the same in the formal and informal sectors, the capital intensity of output in each sector is determined by the relative prices of the formal and informal goods.

\section{A.3 Nash Bargaining Wage determination}

The wages $W_{I, t}$ and $W_{F, t}$ are a weighted average of the steady state wages $\bar{W}_{I}$ and $\bar{W}_{F}$, and the wages obtained as the solution of a Nash bargaining process between workers and intermediate good producers $\tilde{W}_{I, t}$ and $\tilde{W}_{F, t}$ :

$$
\begin{gathered}
W_{I, t}=s_{I} \tilde{W}_{I, t}+\left(1-s_{I}\right) \bar{W}_{I} \\
W_{F, t}=s_{F} \tilde{W}_{F, t}+\left(1-s_{F}\right) \bar{W}_{F} .
\end{gathered}
$$

While it does not affect the steady state wages nor the equilibrium wages computed from a firstorder approximation of the model equations around the steady state, this formulation allows to reduce the volatility of the equilibrium wages, making it easier for the model to match the data.

The bargaining power of both the worker and the firm in sector $s$ is determined by the exogenous, time-invariant parameter $\gamma_{s} \in[0,1]$. The bargaining problem in each sector can be written as:

$$
\max _{\tilde{W}_{s, t}}\left(V_{s, t}-V_{U, t}\right)^{\gamma_{s}} J_{s, t}^{1-\gamma_{s}}
$$

where $V_{s, t}$ is the value for a worker of being employed in sector $s, V_{U, t}$ is the value of unemployment, and $J_{s, t}$ is the marginal value of a worker for the firm. 
Let $\chi_{F, t}^{h}$ and $\chi_{I, t}^{h}$ denote the probabilities for a worker of being hired respectively in the formal and informal sector. Those are given by the ratios of new hires in each sector to the pool of unemployed workers:

$$
\chi_{s, t}=\frac{H_{s, t}}{U_{t-1}+\sigma_{F, t} L_{F, t-1}+\sigma_{I, t} L_{I, t-1}}, \quad s \in(F, I)
$$

where $U_{t-1}$ denotes unemployment at the end of period $t-1$. The values of employment in the formal and informal sectors can then be written as:

$$
\begin{aligned}
V_{F, t}=\left(1-\tau_{F}\right) \tilde{W}_{F, t}+M R S_{F, t}+E_{t}[ & \rho_{t, t+1}\left(\left(1-\sigma_{F, t+1}+\sigma_{F, t+1} \chi_{F, t+1}^{h}\right) V_{F, t+1}\right. \\
& \left.\left.+\sigma_{F, t+1}\left(\chi_{I, t+1}^{h} V_{I, t+1}+\left(1-\chi_{F, t+1}^{h}-\chi_{I, t+1}^{h}\right) V_{U, t+1}\right)\right)\right] \\
V_{I, t}=\tilde{W}_{I, t}+M R S_{I, t}+E_{t}[ & \rho_{t, t+1}\left(\left(1-\sigma_{I, t+1}+\sigma_{I, t+1} \chi_{I, t+1}^{h}\right) V_{I, t+1}\right. \\
& \left.\left.+\sigma_{I, t+1}\left(p_{F, t+1}^{h} V_{F, t+1}+\left(1-\chi_{F, t+1}^{h}-\chi_{I, t+1}^{h}\right) V_{U, t+1}\right)\right)\right] .
\end{aligned}
$$

The value of unemployment is:

$$
V_{U, t}=W_{U, t}+E_{t}\left[\rho_{t, t+1}\left(\left(1-\chi_{F, t+1}^{h}-\chi_{I, t+1}^{h}\right) V_{U, t+1}+\chi_{F, t+1}^{h} V_{F, t+1}+\chi_{I, t+1}^{h} V_{I, t+1}\right)\right] .
$$

Finally, the value for the intermediate good producer of hiring an additional worker is simply equal to the hiring cost, that is $J_{s, t}=H C_{s, t} p_{s, t}^{z}$.

The sharing rules are as follows:

$$
\begin{aligned}
V_{F, t}-V_{U, t} & =\frac{\gamma_{F}}{1-\gamma_{F}}\left(1-\tau_{F}\right) J_{F, t} \\
V_{I, t}-V_{U, t} & =\frac{\gamma_{I}}{1-\gamma_{I}} J_{I, t} .
\end{aligned}
$$

Inserting the value functions in the above sharing rule gives the following equations for the real wage in the formal and informal sectors:

$$
\begin{aligned}
& \tilde{W}_{F, t}=\frac{\gamma_{F}}{1-\gamma_{F}} H C_{F, t} p_{F, t}^{z}+\frac{W_{U, t}}{1-\tau_{F}}+\frac{M R S_{t, F}}{1-\tau_{F}} \\
& +E_{t}\left[\rho_{t, t+1}\left(1-\sigma_{F, t+1}\right)\left(\frac{\gamma_{I}}{1-\gamma_{I}} \frac{\chi_{I, t+1}^{h}}{1-\tau_{F}} H C_{I, t+1} p_{I, t+1}^{z}-\frac{\gamma_{F}}{1-\gamma_{F}}\left(1-\chi_{F, t+1}^{h}\right) H C_{F, t+1} p_{F, t+1}^{z}\right)\right] \\
& \tilde{W}_{I, t}=\frac{\gamma_{I}}{1-\gamma_{I}} H C_{I, t} p_{I, t}^{z}+W_{U, t}+M R S_{t, I} \\
& +E_{t}\left[\rho_{t, t+1}\left(1-\sigma_{I, t+1}\right)\left(\frac{\gamma_{F}}{1-\gamma_{F}}\left(1-\tau_{F}\right) \chi_{F, t+1}^{h} H C_{F, t+1} p_{F, t+1}^{z}-\frac{\gamma_{I}}{1-\gamma_{I}}\left(1-\chi_{I, t+1}^{h} H C_{I, t+1} p_{I, t+1}^{z}\right)\right] .\right.
\end{aligned}
$$

\section{A.4 Retailers}

Formal and informal retailers produce homogeneous formal and informal goods, $Y_{F}$ and $Y_{I}$, using final good varieties $Y_{F}\left(j_{F}\right)$ and $Y_{I}\left(j_{I}\right)$ bought from wholesalers. The production function that 
transforms final goods into final output is given by:

$$
Y_{s, t}=\left[\int_{0}^{N_{s, t}} Y_{s, t}\left(j_{s}\right)^{\frac{\varepsilon_{s}-1}{\varepsilon_{s}}} d j_{s}\right]^{\frac{\varepsilon_{s}}{\varepsilon_{s}-1}}, \quad s \in(F, I)
$$

where $\varepsilon_{s}$ is the (constant) elasticity of substitution between final goods. Solving the cost minimization problem given all final producer prices $P_{s, t}\left(j_{s}\right)$ and $P_{s, t}$ yields the demand for the final good $s:$

$$
Y_{s, t}\left(j_{s}\right)=\left[\frac{P_{s, t}\left(j_{s}\right)}{P_{s, t}}\right]^{-\varepsilon_{s}} Y_{s, t}
$$

The corresponding price index is given by:

$$
P_{s, t}=\left[\int_{0}^{N_{s, t}} P_{s, t}\left(j_{s}\right)^{1-\varepsilon_{s}} d j_{s}\right]^{\frac{1}{1-\varepsilon_{s}}} .
$$

\section{A.5 Wholesale final good producers}

There is a continuum of monopolistically competitive, wholesale formal and informal final good producers owned by the household, indexed by $j_{F} \in\left[0, N_{F, t}\right]$ and $j_{I} \in\left[0, N_{I, t}\right]$. Each firm buys intermediate goods $Z_{F}\left(j_{F}\right)$ and $Z_{I}\left(j_{I}\right)$, to produce different wholesale good varieties $Y_{F}\left(j_{F}\right)$ and $Y_{I}\left(j_{I}\right)$ that are sold to retailers at a price $P_{F}\left(j_{F}\right)$ and $P_{I}\left(j_{I}\right)$, respectively. The wholesalers' production function is linear: $Y_{s}\left(j_{s}\right)=Z_{s}\left(j_{s}\right)$, which implies that $M C_{s, t}=P_{s, t}^{z} / P_{t} \equiv p_{s, t}^{z}$ is the real marginal cost common to all firms in sector $s$.

New entrants in the formal and informal sectors, denoted $N_{F, t}^{e}$ and $N_{I, t}^{e}$, face an exogenous sunk entry cost equal to respectively $E C_{F}$ and $E C_{I}$ units of each final goodIncumbents and new entrants face a probability of bankruptcy $\delta_{F}$ or $\delta_{I}$. This also means that only a $1-\delta_{F}\left(1-\delta_{I}\right)$ fraction of firms that enter the economy in period $t$ starts producing immediately while a $\delta_{F}\left(\delta_{I}\right)$ fraction exits.The number of firms operating each period is then:

$$
N_{s, t}=\left(1-\delta_{s}\right)\left(N_{s, t-1}+N_{s, t}^{e}\right), \quad s \in(F, I) .
$$

When deciding whether to enter or not, prospective entrants compare the present discounted value of their expected post-entry profits to the sunk entry costs. Entry occurs until the firm value is equalized with the entry cost, yielding the free-entry conditions:

$$
E_{t} \sum_{i=0}^{\infty} \rho_{t, t+i}\left(1-\delta_{s}\right)^{i+1} \Pi_{s, t+i}^{f}\left(j_{s}\right)=p_{s, t} E C_{s}\left(1+\xi i_{t}\right), \quad \text { for all firms } j_{s}, \quad s \in(F, I) .
$$

Free entry thus implies that all firms in sector $s$ enjoy the same flow of profits $\Pi_{s, t}^{f}\left(j_{s}\right)=\bar{\Pi}_{s, t}^{f}$ for all $t$. The above equation can be rewritten in a recursive form:

$$
p_{s, t} E C_{s}\left(1+\xi i_{t}\right)=\rho_{t, t+1}\left(1-\delta_{s}\right) E C_{s} E_{t}\left[p_{s, t+1}\left(1+\xi i_{t+1}\right)\right]+\left(1-\delta_{s}\right) \bar{\Pi}_{s, t}^{f},
$$


where

$$
\bar{\Pi}_{s, t}^{f}=\left[\left(\frac{P_{s, t}\left(j_{s}\right)}{P_{t}}-p_{s, t}^{z}\right) Y_{s, t}\left(j_{s}\right)-\frac{\phi_{s}}{2}\left(\frac{P_{s, t}\left(j_{s}\right)}{P_{s, t-1}\left(j_{s}\right)} \frac{1}{\bar{\pi}}-1\right)^{2} \frac{P_{s, t}}{P_{t}} Y_{s, t}\right]
$$

Prices are sticky and wholesale producers face a quadratic price adjustment cost a la Rotemberg (1982). $\bar{\pi}$ is inflation in the steady-state. The parameter $\phi_{s}$ measures the cost of price adjustment in units of the final good $s \in(F, I)$. Final good producers choose the optimal (real) price $p_{s, t}\left(j_{s}\right) \equiv$ $P_{s, t}\left(j_{s}\right) / P_{t}$ to maximize

$E_{t} \sum_{i=0}^{\infty} \rho_{t, t+i}\left[\left(p_{s, t+i}\left(j_{s}\right)-p_{s, t+i}^{z}\right)\left(p_{s, t+i}\left(j_{s}\right) / p_{s, t+i}\right)^{-\varepsilon_{s}}-\frac{\phi_{s}}{2}\left(\frac{p_{s, t+i}\left(j_{s}\right)}{p_{s, t+i-1}\left(j_{s}\right)} \frac{\pi_{t+i}}{\bar{\pi}}-1\right)^{2} p_{s, t+i}\right] Y_{s, t+i}$,

where we substituted for each firm's output $Y_{s, t}\left(j_{s}\right)$. In a symmetric equilibrium all firms behave identically, that is, they all charge the same price $\bar{p}_{s, t}$ and produce the same output $\bar{Y}_{s, t}$. We have thus the following relations between firm-level and aggregate variables:

$$
\begin{gathered}
p_{s, t}\left(j_{s}\right)=\bar{p}_{s, t}=N_{s, t}^{\frac{1}{\varepsilon_{s}-1}} p_{s, t}, \quad s \in(F, I) \\
Y_{s, t}\left(j_{s}\right)=\bar{Y}_{s, t}=N_{s, t}^{\frac{\varepsilon_{s}}{1-\varepsilon_{s}}} Y_{s, t} .
\end{gathered}
$$

Hence aggregate sectoral output $Y_{s, t}$ is increasing with the firms mass $N_{s, t}$.

Similarly, aggregate sectoral profits are increasing with $N_{s, t}$ :

$$
\Pi_{s, t}^{f}=N_{s, t} \bar{\Pi}_{s, t}^{f}, \quad s \in(F, I) .
$$

with

$$
\bar{\Pi}_{s, t}^{f}=\left[\left(\bar{p}_{s, t}-p_{s, t}^{z}\right)\left(\bar{p}_{s, t} / p_{s, t}\right)^{-\varepsilon_{s}}-\frac{\phi_{s}}{2}\left(\frac{\bar{p}_{s, t}}{\bar{p}_{s, t-1}} \frac{\pi_{t}}{\bar{\pi}}-1\right)^{2} p_{s, t}\right] Y_{s, t}, \quad s \in(F, I)
$$

The optimality condition for price-setting can be written as:

$$
\begin{aligned}
& {\left[-\varepsilon_{s}\left(\bar{p}_{s, t}-p_{s, t}^{z}\right) \frac{\bar{p}_{s, t}^{-\varepsilon_{s}-1}}{p_{s, t}^{-\varepsilon_{s}}}+\left(\frac{\bar{p}_{s, t}}{p_{s, t}}\right)^{-\varepsilon_{s}}-\phi_{s} \frac{p_{s, t}}{\bar{p}_{s, t-1}} \frac{\pi_{t}}{\bar{\pi}}\left(\frac{\bar{p}_{s, t}}{\bar{p}_{s, t-1}} \frac{\pi_{t}}{\bar{\pi}}-1\right)\right] Y_{s, t}} \\
& +E_{t}\left[\rho_{t, t+1} \phi_{s} \frac{p_{s, t+1} \bar{p}_{s, t+1}}{\bar{p}_{s, t}^{2}} \frac{\pi_{t+1}}{\bar{\pi}}\left(\frac{\bar{p}_{s, t+1}}{\bar{p}_{s, t}} \frac{\pi_{t+1}}{\bar{\pi}}-1\right) Y_{s, t+1}\right]=0,
\end{aligned}
$$

In steady state, the firm-level optimal price is a markup over marginal costs $\bar{p}_{s}=\mu_{s} p_{s}^{z}$ and profits reduce to $\bar{\Pi}_{s}^{f}=\left(\mu_{s}-1\right) p_{s}^{z} \bar{Y}_{s}$, where $\mu_{s}=\varepsilon_{s} /\left(\varepsilon_{s}-1\right)$. Aggregate sectoral firm profits are increasing in the number of firms $N_{s}$ and sectoral output $Y_{s}: \Pi_{s}^{f}=\left(\mu_{s}-1\right) p_{s}^{z} Y_{s} N_{s}^{1 /\left(1-\varepsilon_{s}\right)}$. 


\section{A.6 Capital producers}

Capital producers are competitive firms that purchase the depreciated capital stock $\left(1-\delta_{k}\right) K_{t-1}$ from the households, buy an amount $I_{t}$ of a composite of imported and domestically produced formal goods to produce new capital, and transform it into new capital via the technology:

$$
K_{t}=\left(1-\delta_{k}\right) K_{t-1}+I_{t}-\frac{\kappa}{2}\left(\frac{I_{t}}{K_{t-1}}-\delta_{k}\right)^{2} K_{t-1}
$$

where $\kappa \geq 0$ is a scale parameter affecting the magnitude of the capital adjustment cost.

Capital producers choose $I_{t}$ to maximize

$$
Q_{t}\left(I_{t}-\frac{\kappa}{2}\left(\frac{I_{t}}{K_{t-1}}-\delta_{k}\right)^{2} K_{t-1}\right)-p_{t}^{I n v} I_{t}
$$

where $p_{t}^{I n v}$ denotes the price of the investment good in units of final consumption.

The first order condition yields the following equation for the price of capital $Q_{t}$ :

$$
Q_{t}\left[1-\kappa\left(\frac{I_{t}}{K_{t-1}}-\delta_{k}\right)\right]=p_{t}^{I n v}
$$

The investment good is a CES aggregate of domestic formal and imported goods:

$$
I_{t}=\left[\alpha_{I}^{\frac{1}{\eta_{I}}} I_{F, t}^{\frac{\eta_{I}-1}{\eta_{I}}}+\left(1-\alpha_{I}\right)^{\frac{1}{\eta_{I}}} I_{f, t} \frac{\eta_{I}-1}{\eta_{I}}\right]^{\frac{\eta_{I}}{\eta_{I}-1}}
$$

where $\alpha_{I} \in[0,1]$ and $\eta_{I}>0, I_{F, T}$ and $I_{f, t}$ are the quantities of respectively domestic formal good and imported good used for investment. It follows that the investment price is

$$
p_{t}^{I n v}=\left[\alpha_{I} p_{F, t}^{1-\eta_{I}}+\left(1-\alpha_{I}\right) p_{f, t}^{1-\eta_{I}}\right]^{\frac{1}{1-\eta_{I}}} .
$$

Total investment cost is given by

$$
p_{t}^{I n v} I_{t}=p_{F, t} I_{F, t}+p_{f, t} I_{f, t} .
$$

Solving the cost minimization problem yields the following investment demand equations:

$$
\begin{gathered}
I_{F, t}=\alpha_{I}\left(p_{F, t} / p_{t}^{I n v}\right)^{-\eta_{I}} I_{t} \\
I_{f, t}=\left(1-\alpha_{I}\right)\left(p_{f, t} / p_{t}^{I n v}\right)^{-\eta_{I}} I_{t}
\end{gathered}
$$

\section{A.7 Government}

The central bank sets the nominal interest rate according to the following feedback rule:

$$
\frac{1+i_{t}}{1+\bar{\imath}}=\left(\frac{\pi_{t}}{\bar{\pi}}\right)^{\nu_{\pi}}\left(\frac{U_{t}}{\bar{U}}\right)^{\nu_{u}} e^{\varepsilon_{i, t}}
$$


where $\bar{\imath}, \bar{\pi}$, and $\bar{U}$ denote the steady-state values of the domestic interest rate, inflation, and unemployment. $\varepsilon_{i, t}$ is a monetary policy shock.

The government finances the unemployment benefit and expenditures $G_{t}$ with the proceeds from the labor income tax and commodity exports, and non-distortionary lump-sum taxation. Like investment, government expenditures are a CES aggregate of domestic formal and imported goods.

$$
G_{t}=\left[\alpha_{G}^{\frac{1}{\eta_{G}}} G_{F, t} \frac{\eta_{G}-1}{\eta_{G}}+\left(1-\alpha_{G}\right)^{\frac{1}{\eta_{G}}} G_{f, t} \frac{\eta_{G}-1}{\eta_{G}}\right]^{\frac{\eta_{G}}{\eta_{G}-1}},
$$

where $G_{F, t}$ and $G_{f, t}$ are the quantities of domestic formal and imported good used for government consumption. The government budget constraint then reads:

$$
p_{t}^{G} G_{t}+W_{U, t} U_{t}+\left(1+r_{t-1}\right) B_{t-1}=T_{t}+\tau_{F} W_{F, t} L_{F, t}+B_{t}+\Xi_{t} p_{E, t} Y_{E, t},
$$

where

$$
p_{t}^{G}=\left[\alpha_{G} p_{F, t}^{1-\eta_{G}}+\left(1-\alpha_{G}\right) p_{f, t}^{1-\eta_{G}}\right]^{\frac{1}{1-\eta_{G}}} .
$$

and $p_{E, t} \equiv P_{E, t} / P_{t}^{*}$ is the world price of commodity endowment $Y_{E_{t}}$ in terms of foreign consumption. ${ }^{20} P_{E, t}$ is the commodity price, expressed in foreign currency. Both $p_{E, t}$ and $Y_{E, t}$ follow exogenous stochastic processes. The total cost of government consumption is

$$
p_{t}^{G} G_{t}=p_{F, t} G_{F, t}+p_{f, t} G_{f, t}
$$

The associated demand functions are:

$$
\begin{gathered}
G_{F, t}=\alpha_{G}\left(p_{F, t} / p_{t}^{G}\right)^{-\eta_{G}} G_{t} \\
G_{f, t}=\left(1-\alpha_{G}\right)\left(p_{f, t} / p_{t}^{G}\right)^{-\eta_{G}} G_{t}
\end{gathered}
$$

The process for the $\log$ of government spending $g_{t} \equiv \log \left(G_{t}\right)$ is given by an $\operatorname{AR}(1)$ process:

$$
\left(g_{t}-\bar{g}\right)=\rho_{G}\left(g_{t-1}-\bar{g}\right)+\varepsilon_{g, t}
$$

where $\varepsilon_{g, t}$ is independently normally distributed with zero mean and standard deviation $\sigma_{G}$. We assume the government adjust the lump-sum tax to stabilize the debt-to-GDP ratio:

$$
T_{t}-\bar{T}=\rho_{T}\left(T_{t-1}-\bar{T}\right)+\left(1-\rho_{T}\right)\left(b_{t}-\bar{b}\right)
$$

where $\bar{T}$ is the steady-state value of the lump-sum tax, $b_{t}=B_{t} /\left(G D P_{t}\right)$ denotes government debt as a share of GDP, and $\bar{b}$ is the steady-state value of that ratio.

\footnotetext{
${ }^{20}$ Defining $p_{E, t}$ in this way, and not in relation to domestic consumption as the other prices, makes it fully exogenous to the modeled economy.
} 


\section{A.8 Rest of the world}

The rest of the world imports domestic formal goods $X_{t}$ and the commodity endowment $Y_{t}^{E}$, exports foreign formal goods $M_{t}$, and sell foreign bonds $B_{t}^{*}$. The domestic economy is small and does not affect foreign output, foreign inflation, or the foreign interest rate, all of which are assumed to be exogenously determined. We assume that the law of one price holds. Hence the price of exports in foreign currency is equal to $P_{F, t} / e_{t}$. The demand for domestic formal exports by the rest of the world is assumed to depend solely on the ratio of export prices to the foreign price index:

$$
X_{t}=\left(\frac{P_{F, t}}{e_{t} P_{t}^{*}}\right)^{-\eta_{x}}=\left(\frac{p_{F, t}}{\Xi_{t}}\right)^{-\eta_{x}}
$$

where $\eta_{x}>1$ represents the price-elasticity of exports. Total imports from the rest of the world are consumed by the household and used by the capital producers and the government:

$$
M_{t}=C_{f, t}+I_{f, t}+G_{f, t} .
$$

The current account balance is given by

$$
\Xi_{t}\left[\varphi\left(B_{t}^{*}\right) B_{t}^{*}-B_{t-1}^{*}\right]=\Xi_{t} r_{t-1}^{*} B_{t-1}^{*}+p_{F, t} X_{t}+\Xi_{t} p_{E, t} Y_{E, t}-p_{f, t} M_{t}
$$

The price of imports is proportional to the real exchange rate,

$$
p_{f, t}=\kappa_{f} \Xi_{t}
$$

where $\kappa_{f}$ is the import price index expressed in foreign consumption; without loss of generality, we will assume that $\kappa_{f}=1$. We define the terms of trade as

$$
\Theta_{t}=\frac{p_{F, t} X_{t}+\Xi_{t} p_{E, t} Y_{E, t}}{\left(X_{t}+Y_{E, t}\right) p_{f, t}}
$$

\section{A.9 Market clearing}

Labor market

$$
U_{t}=1-L_{F, t}-L_{I, t}
$$

Capital market

$$
\sum_{s \in(F, I)} K_{s, t}=K_{t-1}
$$

Formal final good market

$$
Y_{F, t}=C_{F, t}+I_{F, t}+G_{F, t}+X_{t}+N_{F, t}^{e} E C_{F}+\frac{\phi_{F}}{2}\left(\frac{\bar{p}_{F, t}}{\bar{p}_{F, t-1}} \frac{\pi_{t}}{\bar{\pi}}-1\right)^{2} N_{F, t} Y_{F, t}
$$

Informal final good market

$$
Y_{I, t}=C_{I, t}+N_{I, t}^{e} E C_{I}+\frac{\phi_{I}}{2}\left(\frac{\bar{p}_{I, t}}{\bar{p}_{I, t-1}} \frac{\pi_{t}}{\bar{\pi}}-1\right)^{2} N_{I, t} Y_{I, t}
$$




\section{Intermediate good markets}

The quantity of intermediate good inputs after paying for the hiring costs of the intermediate good producers equals the quantity of final goods produced by the wholesale final good producers in each sector:

$$
Z_{F}-H C_{F} H_{F, t}=\int_{0}^{N_{F, t}} Z_{F}\left(j_{F}\right) d j_{F}=\int_{0}^{N_{F, t}} Y_{F}\left(j_{F}\right) d j_{F}=\int_{0}^{N_{F, t}} N_{F, t}^{\frac{\varepsilon_{F}}{1-\varepsilon_{F}}} Y_{F, t} d j_{F}=Y_{F, t} N_{F, t}^{\frac{1}{1-\varepsilon_{F}}}
$$

and

$$
Z_{I}-H C_{I} H_{I, t}=Y_{I, t} N_{I, t}^{\frac{1}{1-\varepsilon_{I}}} .
$$

Aggregate GDP, expressed in units of consumption, is defined as

$$
G D P_{t}=p_{F, t} Y_{F, t}+p_{I, t} Y_{I, t}+\Xi_{t} p_{E, t} Y_{E, t} \quad \text { (supply side) }
$$

Alternatively,

$$
G D P_{t}=C_{t}+p_{t}^{I n v} I_{t}+p_{t}^{G} G_{t}+p_{F, t} X_{t}+\Xi_{t} p_{E, t} Y_{E, t}-p_{f, t} M_{t}
$$

$+p_{F, t}\left[N_{F, t}^{e} E C_{F}+\frac{\phi_{F}}{2}\left(\frac{\bar{p}_{F, t}}{\bar{p}_{F, t-1}}-1\right)^{2} N_{F, t} Y_{F, t}\right]+p_{I, t}\left[N_{I, t}^{e} E C_{I}+\frac{\phi_{I}}{2}\left(\frac{\bar{p}_{I, t}}{\bar{p}_{I, t-1}}-1\right)^{2} N_{I, t} Y_{I, t}\right]$ (demand side)

The model includes 66 endogenous variables determined by the dynamic system of 66 equations identified above: $C_{t}, C_{h, t}, C_{f, t}, C_{F, t}, C_{I, t}, p_{h, t}, p_{f, t}, r_{t}, i_{t}, B_{t}, B_{t}^{*}, \pi_{t}, R_{t}^{k}, Q_{t}, \rho_{t, t+1}, U_{t}, T_{t}$, $\left\{M R S_{s, t}, Z_{s, t}, H C_{s, t}, \Pi_{s, t}^{i}, p_{s, t}^{z}, L_{s, t}, H_{s, t}, K_{s, t}, W_{s, t}, \tilde{W}_{s, t}, \chi_{s, t}, N_{s, t}, N_{s, t}^{e}, Y_{s, t}, \bar{\Pi}_{s, t}^{f}, \Pi_{s, t}^{f}, \bar{p}_{s, t}, p_{s, t}\right\}_{s \in F, I}$, $p_{t}^{I n v}, K_{t}, I_{t}, I_{F, t}, I_{f_{t}}, p_{t}^{G}, G_{F, t}, G_{f, t}, X_{t}, M_{t}, \Xi_{t}, \Theta_{t}, G D P_{t}$.

We define real GDP as

$$
R G D P_{t}=G D P_{t}\left(\frac{G \bar{D} P}{\bar{p}_{F} \bar{Y}_{F} p_{F, t}+\bar{p}_{I} \bar{Y}_{I} p_{I, t}+\bar{\Xi} \bar{p}_{E} \bar{Y}_{E} \Xi_{t} p_{E, t}}\right)
$$

where $\bar{x}$ denotes the steady state of variable $x$. 
In addition to the stochastic process for $G_{t}$, we consider the following processes for $\zeta_{C, t}, \theta_{a, t}, \theta_{I, t}$, $\sigma_{F, t}, \sigma_{I, t}, p_{E, t}$, and $r_{t}^{*}$.

$$
\begin{aligned}
& \log \zeta_{C, t}=\left(1-\rho_{\zeta_{C}}\right) \log \bar{\zeta}_{C}+\rho_{\zeta_{C}} \log \zeta_{C, t-1}+\epsilon_{\zeta_{C}} \\
& \log \theta_{a, t}=\left(1-\rho_{\theta_{a}}\right) \log \bar{\theta}_{a}+\rho_{\theta_{a}} \log \theta_{a, t-1}+\epsilon_{\theta_{a}} \\
& \log \theta_{I, t}=\log \bar{\theta}_{I}+\epsilon_{\theta_{I}} \\
& \log \sigma_{F, t}=\left(1-\rho_{\sigma_{F}}\right) \log \bar{\sigma}_{F}+\rho_{\sigma_{F}} \log \sigma_{F, t-1}+\epsilon_{\sigma_{F}} \\
& \log \sigma_{I, t}=\left(1-\rho_{\sigma_{I}}\right) \log \bar{\sigma}_{I}+\rho_{\sigma_{I}} \log \sigma_{I, t-1}+\epsilon_{\sigma_{I}} \\
& \log \left(1+r_{t}^{*}\right)=\left(1-\rho_{r^{*}}\right) \log \left(1+\bar{r}^{*}\right)+\rho_{r^{*}} \log \left(1+r_{t-1}^{*}\right)+\epsilon_{r^{*}} \\
& \log p_{E, t}=\left(1-\rho_{p_{E}}\right) \log \left(\bar{p}_{E}\right)+\rho_{p_{E}} \operatorname{lo}\left(p_{E, t-1}\right)+\epsilon_{p_{E}}
\end{aligned}
$$

where $\epsilon_{\zeta_{C}}, \epsilon_{\theta_{a}}, \epsilon_{\theta_{I}}, \epsilon_{\sigma_{F}}, \epsilon_{\sigma_{I}}, \epsilon_{r^{*}}, \epsilon_{p_{E}}$ are i.i.d. shocks with zero mean.

In the model simulations, $W U_{t}$ and $Y_{E, t}$ are set equal to their steady-state values $\overline{W U}$ and $\bar{Y}_{E}$. Without loss of generality, $\theta_{F, t}$ is fixed and equal to 1 . 


\section{B Additional Tables}

Table B1: Fixed Parameters

\begin{tabular}{|c|c|c|c|}
\hline Parameter & Parameter Description & Value & Source \\
\hline$\beta$ & Discount factor & 0.99 & Gonzales et al. (2013) \\
\hline$h$ & Habit persistence parameter & 0.7 & Smets and Wouters (2007) \\
\hline$\xi_{F} ; \xi_{I}$ & Disutility of labor parameters & 1.4 & Leyva and Urrutia (2020) \\
\hline$\lambda_{F} ; \lambda_{I}$ & Frish labor supply elasticities & 1 & Christiano et al. (2013) \\
\hline$\varphi_{B}$ & Foreign bond transaction cost parameter & 1 & Without loss of generality \\
\hline$\varepsilon_{s}(F)$ & Elasticity of subst. btw. formal good varieties & 8 & Markup of 12 percent \\
\hline$\varepsilon_{s}(I)$ & Elasticity of subst. btw. informal good varieties & 20 & Markup of 5 percent \\
\hline$\eta_{c}$ & Elasticity of subst. btw $C_{h}$ and $C_{f}$ & 1.25 & Feenstra et al. (2018) \\
\hline$\alpha_{c}$ & Share of domestically produced goods in $C$ & 0.87 & Gonzales et al. (2013) \\
\hline$\mu$ & Elasticity of subst. btw. $C_{F}$ and $C_{I}$ parameter & 0.6 & To match labor market outcomes \\
\hline$\omega$ & Weight of informal good in $C_{h}$ & 1 & Without loss of generality \\
\hline$\zeta_{C}$ & Steady state value of preference shock & 1 & Without loss of generality \\
\hline$\theta_{a}$ & Steady state aggregate TFP & 0.35 & To match labor market outcomes \\
\hline$\theta_{F}$ & Steady state TFP in formal sector & 1 & To match labor market outcomes \\
\hline$\theta_{I}$ & Steady state TFP in informal sector & 0.7 & To match labor market outcomes \\
\hline$\delta_{k}$ & Capital depreciation parameter & 0.03 & Gonzales et al. (2013) \\
\hline$\kappa$ & Capital adjustment cost parameter & 0.5 & To match investment std. rel. to GDP \\
\hline$\psi_{F} ; \psi_{I}$ & Capital income shares in production & 0.34 & Penn World Tables 9 \\
\hline$\delta_{F}$ & Bankruptcy rate in the formal sector & 0.03225 & Ulyssea (2018) \\
\hline$\delta_{I}$ & Bankruptcy rate in the informal sector & 0.0875 & Ulyssea (2018) \\
\hline$\eta_{I}$ & Elasticity of subst. btw $I_{F}$ and $I_{f}$ & 1.25 & Feenstra et al. (2018) \\
\hline$\alpha_{I}$ & Share of domestically produced goods in I & 0.6 & Gonzales et al. (2013) \\
\hline$\sigma_{F}$ & Steady state firing probability in formal sector & 0.088 & Leyva and Urrutia (2020) \\
\hline$\sigma_{I}$ & Steady state firing probability in informal sector & 0.16 & Shorter job duration informal \\
\hline$\gamma_{F}$ & Bargaining power of workers in formal sector & 0.45 & Ulyssea $(2018)$ \\
\hline$\gamma_{I}$ & Bargaining power of workers in informal sector & 0.15 & Ulyssea (2018) \\
\hline$\beta_{F}$ & Intensity of hiring cost parameter in formal sector & 0.9 & To match labor market outcomes \\
\hline$\beta_{I}$ & Intensity of hiring cost parameter in informal sector & 0.3 & To match labor market outcomes \\
\hline$\alpha_{F} ; \alpha_{I}$ & Elasticity of hiring cost & 1 & Blanchard and Gali (2010) \\
\hline$\phi_{F} ; \phi_{I}$ & Price adjustment cost parameters & 300 & Lombardo and Vestin (2008) \\
\hline$\pi$ & Steady state inflation & 1.007417 & 3 percent annual inflation \\
\hline$\nu_{\pi}$ & Weight of inflation in Taylor rule & 1.5 & Standard \\
\hline
\end{tabular}

To be continued on the next page 
Table B1: Fixed Parameters (continued)

\begin{tabular}{cccc}
\hline \hline Parameter & Parameter Description & Value & Source \\
\hline$\nu_{u}$ & Weight of unemployment in Taylor rule & 0.5 & Standard \\
$\tau_{F}$ & Payroll tax rate & 0.16 & 16 percent payroll tax \\
$\eta_{g}$ & Elasticity of subst. btw $G_{F}$ and $G_{f}$ & 1.25 & Feenstra et al. (2018) \\
$\alpha_{g}$ & Share of domestically produced goods in G & 0.87 & Gonzales et al. (2013) \\
$\rho_{T}$ & Persistence of deviations from steady-state lump sum tax & 0.5 & Without loss of generality \\
$\eta_{x}$ & Price elasticity of exports & 1.2 & Fernandez et al. (2018) \\
$\kappa_{f}$ & Price of imports-to-RER parameter & 1 & Without loss of generality \\
\hline \hline
\end{tabular}

Table B2: Calibrated Parameters

\begin{tabular}{cccccc}
\hline \hline Target Ratio & Target Value & Source & Parameter & Parameter Description & Parameter Value \\
\hline$\frac{E C_{F}}{Y_{F}}$ & 3 & $\mathrm{WB}$ & $E C_{F}$ & Firm Entry Cost in the Formal Sector & 1.09 \\
$\frac{E C_{I}}{Y_{I}}$ & 0.5 & $\mathrm{WB}$ & $E C_{I}$ & Firm Entry Cost in the Informal Sector & 0.12 \\
$\frac{G}{G D P}$ & 0.16 & $\mathrm{IMF}$ & $\bar{G}$ & Government Consumption in Steady State & 0.15 \\
$\frac{B}{G D P}$ & 0.4 & $\mathrm{IMF}$ & $\bar{B}$ & Stock of Domestic Debt in Steady State & 0.52 \\
$\frac{Y_{E}}{G D P}$ & 0.08 & $\mathrm{IMF}$ & $\bar{Y}_{E}$ & Commodity Sector Output in Steady State & 0.41 \\
$\frac{B^{*}}{G D P}$ & -0.25 & $\mathrm{IMF}$ & $\bar{B}^{*}$ & Net international position in Steady State & -1.27 \\
$\frac{W U}{W_{F}}$ & 0.05 & & $W U$ & Unemployment Benefit & 0.04 \\
\hline \hline
\end{tabular}

Note: The calibration of $\frac{E C_{F}}{Y_{F}}$ and $\frac{E C_{I}}{Y_{I}}$ draws on the methodology from Barseghyan and DiCecio (2011) and data are from the World Bank's Doing Business Survey. 'IMF' refers to the International Monetary Fund. 'WB' refers to the World Bank. 
Table B3: Shock Processes

\begin{tabular}{cccc}
\hline \hline Parameter & Parameter Description & Value & Source \\
\hline$\rho_{p_{E}}$ & Persistence of commodity price shock & 0.93 & Based on Colombian data \\
$\rho_{\zeta_{C}}$ & Persistence of preference shock & 0.086 & SMM Estimation \\
$\rho_{\theta_{a}}$ & Persistence of aggregate TFP shock & 0.995 & SMM Estimation \\
$\rho_{\sigma_{F}}$ & Persistence of formal sector firing probability shock & 0.628 & SMM Estimation \\
$\rho_{\sigma_{I}}$ & Persistence of informal sector firing probability shock & 0.021 & SMM Estimation \\
$\rho_{G}$ & Persistence of government consumption shock & 0.837 & SMM Estimation \\
$\rho_{r^{*}}$ & Persistence of foreign interest rate shock & 0.306 & SMM Estimation \\
$\sigma\left(\epsilon_{p_{E}}\right)$ & Std. dev. of commodity price shock & 0.097 & SMM Estimation \\
$\sigma\left(\epsilon_{\zeta_{C}}\right)$ & Std. dev. of preference shock & 0.008 & Based on Colombian data \\
$\sigma\left(\epsilon_{\theta_{a}}\right)$ & Std. dev. of aggregate TFP shock & 0.019 & SMM Estimation \\
$\sigma\left(\epsilon_{\theta_{I}}\right)$ & Std. dev. of informal sector TFP shock & 0.006 & SMM Estimation \\
$\sigma\left(\epsilon_{\sigma_{F}}\right)$ & Std. dev. of formal sector firing probability shock & 0.000 & SMM Estimation \\
$\sigma\left(\epsilon_{\sigma_{I}}\right)$ & Std. dev. of informal sector firing probability shock & 0.001 & SMM Estimation \\
$\sigma\left(\epsilon_{g}\right)$ & Std. dev. of government consumption shock & 0.025 & SMM Estimation \\
$\sigma\left(\epsilon_{r^{*}}\right)$ & Std. dev. of foreign interest rate shock & 0.003 & SMM Estimation \\
$\sigma\left(\epsilon_{i}\right)$ & Std. dev. of domestic interest rate shock & 0.006 & Based on Colombian data \\
\hline \hline
\end{tabular}

